BRUNO HANNUD

MODELAGEM TERMODINÂMICA DE CHAMAS ADIABÁTICAS DE PRÉ-MISTURA DE DUAS FATIAS: O CASO DA CHAMA

REVERSÍVEL E O DA CHAMA DE MÁXIMA IRREVERSIBILIDADE

São Paulo 
BRUNO HANNUD

\section{MODELAGEM TERMODINÂMICA DE CHAMAS ADIABÁTICAS DE PRÉ-MISTURA DE DUAS FATIAS: O CASO DA CHAMA REVERSÍVEL E O DA CHAMA DE MÁXIMA IRREVERSIBILIDADE}

Tese apresentada à Escola Politécnica da Universidade de São Paulo para obtenção do Titulo de Doutor em Ciências

Área de Concentração:

Engenharia Mecânica de Energia e Fluidos

Orientador:

Prof. Dr. Marcos de Mattos Pimenta

São Paulo 
Este exemplar foi revisado e corrigido em relação à versão original, sob responsabilidade única do autor e com a anuência de seu orientador.

São Paulo, de de

Assinatura do autor:

Assinatura do orientador:

Catalogação-na-publicação

Hannud, Bruno

Modelagem Termodinâmica de chamas adiabáticas de pré-mistura de duas fatias: o caso da chama reversível e o da chama de máxima irreversibilidade / B. Hannud -- versão corr. -- São Paulo, 2017.

$110 \mathrm{p}$.

Tese (Doutorado) - Escola Politécnica da Universidade de São Paulo. Departamento de Engenharia Mecânica.

1.Chamas 2.Exergia 3.Otimização I.Universidade de São Paulo. Escola Politécnica. Departamento de Engenharia Mecânica II.t. 


\section{Dedicatória}

In memoriam, dedico esse trabalho aos meus pais, que sempre valorizaram 0 estudo e a quem devo meu gosto por ele. A curiosidade foi uma consequência.

Dedico esse trabalho também à minha filha Emmanuelle que me ensinou mais do que eu poderia aprender nos livros. 


\section{Agradecimentos}

Agradeço meu médico por ter me acompanhado nessa caminhada. Agradeço também o meu orientador Prof. Dr. Marcos de Mattos Pimenta por ter-me permitido trabalhar com liberdade, sem a qual, não teria conseguido desenvolver esse trabalho. 
Using a term like nonlinear science is like referring to the bulk of zoology as the study of non-elephant animals.

Stanislaw Ulam 


\section{Resumo}

O presente trabalho procura estudar e compreender os processos reativos de chama, tentando identificá-los através de uma abordagem químico termodinâmica, em contraposição às análises clássicas, puramente cinético-químicas. Estas são justificadas por se considerar este tipo de fenômeno como existindo em condições distantes da condição de equilíbrio termodinâmico e não passíveis de análise termodinâmica, coisa que, através desta investigação, pretende-se questionar. Neste estudo, considerou-se a chama como ocorrendo em um escoamento unidimensional ideal, em regime permanente, em fluido perfeito, i.e. não há viscosidade e dividiu-se a chama em fatias, em que a exergia química era transformada em exergia térmica, em se adaptando "o problema do tijolo aquecido" (ou "hot brick problem"). O processo reativo global de chama adiabática foi, por evidência experimental, considerado como sendo bi-variante i.e. completamente determinado com a definição da pressão e da temperatura dos reagentes, conhecidos a priori, em espécie e em quantidade. O teorema de Duhem ${ }^{1}$ nos garante, portanto, que caso se estabeleça o equilíbrio, este estaria determinado. Aqui se procurou reunir subsídios para sua identificação. Investigaram-se a modelagem de chamas adiabáticas e reversíveis de duas fatias, consideradas como meio efetivo, em se igualando a exergia química à exergia térmica, bem como o que se considerou como sendo chamas adiabáticas de duas fatias de máxima irreversibilidade interna. Para a chama adiabática irrever-

\footnotetext{
${ }^{1}$ para qualquer sistema fechado formado inicialmente por espécies químicas com quantidade de massa especificada, o estado de equilíbrio é completamente determinado quando são fixadas quaisquer duas variáveis independentes.
} 
sível obteve-se temperaturas de ignição próximas à temperatura de autoignição para 4 de 6 combustíveis.

Por fim, conclui-se que a chama contínua não é o limite da chama irreversível de infinitas fatias. Enquanto que aquela tem irreversibilidade máxima, segundo o modelo apresentado, a irreversibilidade desta é um máximo relativo.

Palavras-chave: Chamas. Exergia. Otimização. 


\section{Abstract}

The present study attempts at an understanding of the reactive processes within a flame. A chemical thermodynamics approach is employed in juxtaposition to the classical analysis which are purely chemical kinetic. These are justified because this phenomenum is considered to take place far from equilibrium conditions and not subject to thermodynamic analysis. This fact will be questioned in this study. A one-dimensional, ideal and steady flow flame was considered. The reactive process of an adiabatic flame was, by experimental evidence, considered to possess two degrees of freedom, i.e it would be completely determined by defining the reactants' pressure and temperature, whose species and quantities were a priori known. Duhem's theorem ${ }^{2}$ tells us that if equilibrium is estabilished, it would be fully determined. An adiabatic and reversible two-sliced flame (the effective medium) was determined by equating the chemical exergy of the flame to the physical exergy of the two slices relative to the ignition point. Also, the constrained extremum of the difference between the chemical and physical exergies allowed the relative maximum of an internally irreversible adiabatic flame to be determined. For the irreversible flame, close simulation of the autoignition temperature for 4 of 6 fuels was obtained.

Finally, the conclusion that a continuous flame is not the limit of an irreversible flame with infinite slices is demonstrated. Whilst that flame is the flame with maximum irreversibility, this flame has a relative maximum of internal irreversibility.

\footnotetext{
${ }^{2}$ for any closed system initially formed by chemical species with specified quantity, the state of equilibrium is fully determined once two independent properties are fixed.
} 
Keywords: Exergy. Flames. Optimization. 


\section{LISTA DE FIGURAS}

1.1 Estrutura de uma chama de pré-mistura metano-ar determinada utilizando métodos assintóticos, extraído de (BUCKMASTER et al.[2005)]. . . . . . . . . . . . . . . . . . . 20

1.2 Atraso calculado no tempo de ignição de misturas de heptanoar utilizando esquemas cinéticos com (CURRAN et al. [1998) e sem (HELD; MARCHESE; DRYER]1997) mecanismos de baixa temperatura, mostrando a importância do comportamento de coeficiente negativo de temperatura. . . . . . . . . . . . . . . . . 22

1.3 Compilação do número de reações em função do número de espécies para mecanismos de hidrocarbonetos $\mathrm{C} 1-\mathrm{C} 8$, mostrando uma relação aproximadamente linear, extraído de (LAW, 2007)] . . . . 24

1.4 Representação pictórica do equilíbrio puntuado (BAK, 1996)] . . . 27

1.5 Representação da Lei de Potência para uma distribuição de avalanches, por tamanho, em um modelo de montes de areia (BAK, 1996) . . . . . . . . . . . . . . . . . . . . . . . 29

3.1 Distância mínima de propagação de chama, extraído de (ARPACl; SELAMET[1988) [ . . . . . . . . . . . . . . . . . . . . . . . . . 52

3.2 Caixa de equil'ibrio de Van't Hoff, extraído de KOTAS (1985)] . . 66

3.3 Frações molares de $\mathrm{H}_{2}, \mathrm{O}_{2}$ e $\mathrm{H}_{2} \mathrm{O}$ no caso de equilíbrio contínuo 67 
4.1 A chama de duas fatias . . . . . . . . . . . . . . . . . 74

4.2 A referência exergética . . . . . . . . . . . . . . . . 75

4.3 O problema do tijolo aquecido . . . . . . . . . . . . . 77

4.4 Figura mostrando a interface, ou caixa de equilíbrio de Van't Hoff. 78

4.5 Figura mostrando os reservatórios, com estado incicial e final (pontilhado), bem como o estado intermediário (com $\dot{Q}_{L}$ e $\left.\dot{Q}_{H}\right)$. $\quad 78$

5.1 Gráfico do grau de conversão em equilíbrio em função da temperatura de equilíbrio, segundo WINTERBOTTOM; KING (1999).). 88

5.2 Gráfico mostrando o grau de conversão adiabática de equilíbrio, segundo WINTERBOTTOM; KING (1999). . . . . . . . . . . . . 89

7.1 Gráfico esquemático de um sistema em evolução por equilíbrio pontuado (O'NEIL, 2017)] . . . . . . . . . . . . . . . . 102 


\section{LISTA DE TABELAS}

3.1 Tipos de Chamas . . . . . . . . . . . . . . . . . . . 33

3.2 Parte do mecanismo de oxidação de $\mathrm{H}_{2}$ com $\mathrm{O}_{2}$, extraído de (KONNOV, 2008)] . . . . . . . . . . . . . . 38

5.1 Comparativo das temperaturas de ignição da chama de máxima irreversibilidade com a temperatura de autoignição . . . . . . . . 91

5.2 Comparativo das temperaturas de ignição da chama de máxima irreversibilidade com a temperatura de ignição da chama reversível 92 


\section{LISTA DE SÍMBOLOS}

$\dot{B}_{\text {quim }} \quad$ taxa de exergia química do combustível

$\dot{B}_{t e r m} \quad$ taxa de exergia térmica das fatias

$\dot{B}_{\text {transf.calor }}$ taxa de exergia referente à troca de calor

$\dot{Q}_{R} \quad$ taxa de troca de calor reversível da reação à $T_{R}$

$[\mathrm{W}]$

$\lambda \quad$ multiplicador de Lagrange da restrição de igualdade da chama irreversível

$\mu_{i_{0}}$ potencial químico das espécies no ambiente

$\left[\frac{J}{m o l}\right]$

$K_{0}$ constante de equilíbrio da reação a $T_{0}$

$n_{i}$ número de mol dos produtos de reação

$T_{0} \quad$ temperatura absoluta do ambiente

$T_{H} \quad$ temperatura absoluta da fatia quente

$[\mathrm{K}]$

$T_{L} \quad$ temperatura absoluta da fatia fria

$T_{a d_{e q}} \quad$ temperatura de chama adiabática de equilíbrio 
$T_{i g n} \quad$ temperatura absoluta na superfície de ignição

$T_{i g n_{\text {irrevestac }}}$ temperatura absoluta da superfície de ignição da chama de irreversibilidade estacionária

$X_{H_{2}} \quad$ grau de conversão do $H_{2}$

$X_{H_{2} q} \quad$ grau de conversão de $H_{2}$ de equilíbrio

$x_{i g n_{i}} \quad$ fração molar da espécies químicas na superfície de ignição

L Lagrangeano da chama adiabática irreversível

R constante universal dos gases $\quad\left[\frac{J}{\mathrm{molK}}\right]$

$\bar{c}_{p_{\text {prod }}} \quad$ calor específico médio dos produtos a pressão constante $\left[\frac{J}{\operatorname{molK}}\right]$

$\bar{c}_{p_{\text {reag }}} \quad$ calor específico médio dos reagentes a pressão constante $\left[\frac{\mathrm{J}}{\mathrm{molK}}\right]$

$n_{H_{2}} \quad$ número de mol de $H_{2} \quad$ [mol]

$\dot{n}_{\text {prod }} \quad$ fluxo em mol dos produtos $\quad\left[\frac{\mathrm{mol}}{\mathrm{s}}\right]$

$\dot{n}_{\text {reag }} \quad$ fluxo em mol dos reagentes $\quad\left[\frac{\mathrm{mol}}{\mathrm{s}}\right]$

$\dot{W}_{\text {perdido }} \quad$ potência perdida pelo sistema $\quad$ [W]

$T_{R} \quad$ temperatura absoluta de referência $\quad[\mathrm{K}]$

$\dot{S}_{g e r} \quad$ taxa da entropia gerada pelo sistema $\quad\left[\frac{W}{K}\right]$

$\Delta H^{0}{ }_{R} \quad$ variação de entalpia padrão de reação [J]

$\Delta G^{0}{ }_{R} \quad$ variação de energia de Gibbs padrão de reação [J]

$\left[\dot{W}_{x}\right]_{\text {MAX }}$ potência química reversível $\quad[\mathrm{W}]$ 
$\Delta \dot{G}_{R}^{0} \quad$ taxa de variação da energia de Gibbs padrão da reação [W]

$\Delta \dot{S}_{R}^{0} \quad$ taxa de variação da entropia padrão da reação $\quad\left[\frac{W}{K}\right]$

$\Delta g_{R}^{0} \quad$ variação da energia de Gibbs padrão específica da reação $\left[\frac{J}{m_{\text {ol }} \text { comb }}\right]$

$\Delta h_{R}^{0} \quad$ variação de entalpia padrão específica da reação $\quad\left[\frac{J}{m_{\text {ol }} \text { comb }}\right]$

$\Delta s_{R}^{0} \quad$ variação de entropia padrão específica da reação $\quad\left[\frac{J}{m_{\text {ol }} l_{c o m b} K}\right]$ 


\section{Sumário}

\begin{tabular}{|lll}
\hline 1 & INTRODUÇÃO E MOTIVAÇÃO & 19
\end{tabular}

$1.1 \quad$ INTRODUÇÃO . . . . . . . . . . . . . . . . . . . . . . 19

1.2 MOTIVAÇÃO . . . . . . . . . . . . . . . . . . 26

\begin{tabular}{|lll}
2 & OBJETIVOS & 31
\end{tabular}

2.1 OBJETIVO GERAL $\ldots \ldots \ldots \ldots \ldots \ldots$

2.2 OBJETIVOS ESPECÍFICOS . . . . . . . . . . . . . . . . 31

3 A MODELAGEM TERMODINÂMICA DE CHAMAS: REVISÃO BIBLIOGRÁFICA 33

3.1 INTRODUÇÃO . . . . . . . . . . . . . . . . . . . . . . . . 33

3.2 MODELAGEM DE CHAMAS DE PRÉ-MISTURA … . . . . 34

3.3 MODELAGEM TERMODINÂMICA DE TEMPERATURA DE CHAMA ADIABÁTICA . . . . . . . . . . . . . . . . . . . 39

3.4 MODELAGEM PSEUDO-TERMODINÂMICA E QUESTÕES DE EQUILÍBRIO LOCAL $\ldots \ldots \ldots$

3.5 A ABORDAGEM EXERGÉTICA E AS CHAMAS . . . . . . . . . 41

3.5.1 Análise exergética: o estado de referência . . . . . . . . 4 44

3.5 .2 Geração de entropia em chamas . . . . . . . . . . . . . 51

3.5 .3 Princípios de extremos de geração de entropia . . . . . 60 
3.5.4 O Conceito de chama de pré-mistura reversível . . . . . . 63

3.5 .5 A chama contínua . . . . . . . . . . . . . . . 66

3.6 CHAMAS CONTÍNUAS . . . . . . . . . . . . . . . . . 66

4 METODOLOGIA: MÉTODOS E MATERIAIS 68

4.1 MÉTODOS . . . . . . . . . . . . . . . . . . 69

4.1 .1 A chama objeto do presente estudo . . . . . . . . . . . . 69

4.1 .2 O estado de referência . . . . . . . . . . . . . . . . . . . 73

4.1 .3 Os subsistemas e o ambiente . . . . . . . . . . . . . . 76

4.1.4 Método para se determinar a chama adiabática reversível 79

4.1.5 Método para se determinar o ponto estacionário da chama adiabática irreversível . . . . . . . . . . . . . . . . 79

4.1 .6 Comentários . . . . . . . . . . . . . . . . . . . . . . . . 80

5 RESULTADOS E DISCUSSÃO 83

5.1 PONTO DE IGNIÇÃO COMO REFERÊNCIA . . . . . . . . . . . . 84

5.1 .1 A exergia de ignição . . . . . . . . . . . . . . . 85

5.2 CHAMA ADIABÁTICA DE EQUILÍBRIO (CHAMA DE UMA FATIA) . . . . . . . . . . . . . . . . . . . . 85

5.3 CHAMA ADIABÁTICA REVERSÍVEL DE DUAS FATIAS . . . . 88

5.4 CHAMA ADIABÁTICA DE DUAS FATIAS DE MÁXIMA IRREVERSIBILIDADE . . . . . . . . . . . . . . . . . . . . . . 92

5.4.1 Um pouco mais de Chamas contínuas . . . . . . . . . . . 96

\begin{tabular}{lll}
\hline 6 & CONCLUSÕES & 98
\end{tabular}

7 SUGESTÃO DE TRABALHOS FUTUROS 101

\begin{tabular}{ll}
\hline Referências Bibliográficas & 103
\end{tabular} 


\section{Capítulo 1}

\section{Introdução e Motivação}

\subsection{Introdução}

Chamas (vide figura 1.1 maioria dos processos reativos ocorrem entre uma distância de menos de um milímetro e levando um tempo de em torno de 10 milisegundos. Normalmente, dezenas de espécies químicas estão envolvidas e os mecanismos cinéticos mais completos de hidrocarbonetos contam com centenas, senão milhares de reações.

Para lidar com essa "característica", a abordagem clássica de modelagem de

${ }^{1}$ onde $T_{u}$ é a temperatura dos reagentes; $T_{o}$, a temperatura de ignição; $T_{b}$, a temperatura dos produtos - no caso de uma chama adiabática, a temperatura de chama adiabática; $S_{L}$, a velocidade de chama laminar ${ }^{2} x$, a distância até o ponto de ignição; $\delta_{L}$, a espessura característica de chama $\frac{D_{T}}{S_{L}}$, onde $D_{T}$ é a difusividade térmica representativa.

${ }^{2}$ a velocidade com que a frente de chama se desloca em relação aos reagentes em estado de repouso. 


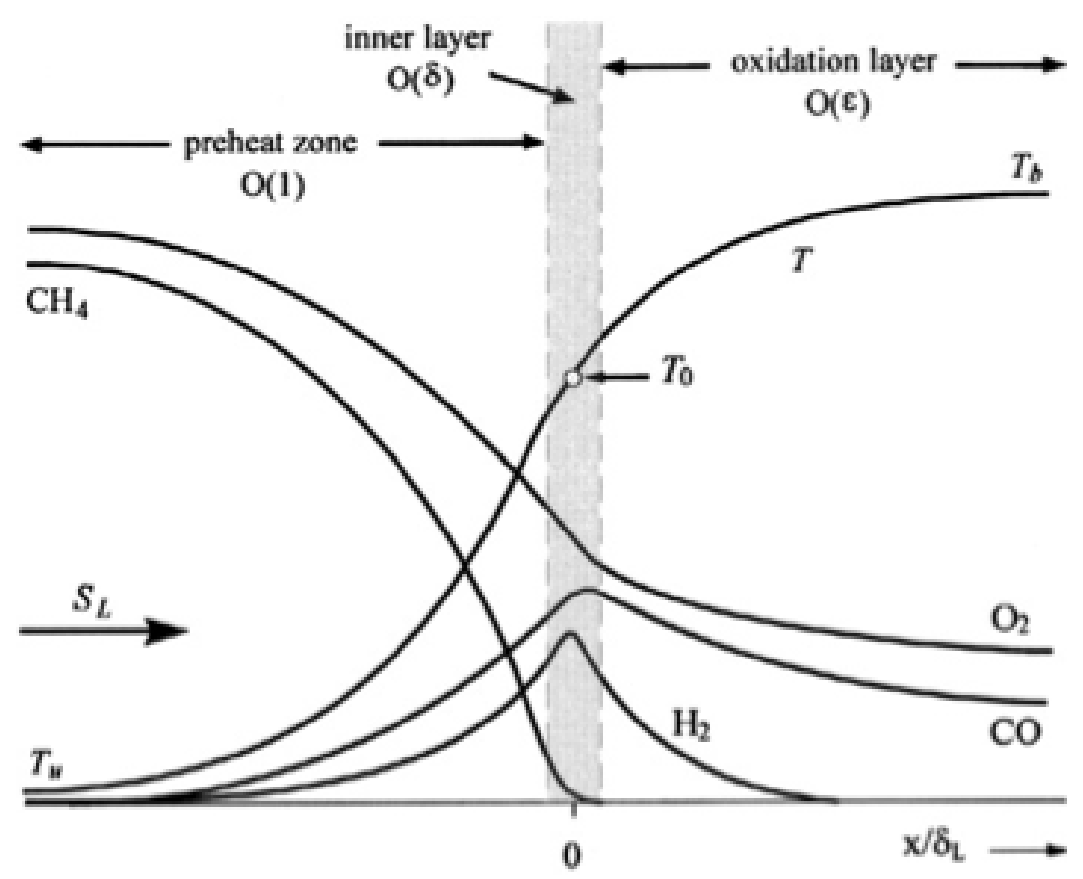

Figura 1.1: Estrutura de uma chama de pré-mistura metano-ar determinada utilizando métodos assintóticos, extraído de (BUCKMASTER et al., 2005)

seus processos reativos baseia-se no uso do arsenal cinético-químico, utilizandose de "força computacional", feitos no âmbito dos processos de simulação e que envolvem a resolução numérica de equações diferenciais que modelam o processo de geração, advecção e difusão de espécies químicas. Como complicador, as taxas de reação são funções normalmente não lineares das frações molares das espécies envolvidas (WARNATZ; MAAS; DIBBLE, 2006).

Apesar disso, com o rápido avanço da capacidade computacional e dos algoritmos, melhoraram significativamente as previsões quantitativas de perfis de chama. Hoje, consegue-se fazer simulações de fenômenos relativamente complexos como o de escoamentos turbulentos em motores, com simplificações moderadas, por exemplo em WESTBROOK et al. (2005). Assim, com o previsível crescimento da capacidade computacional, pode-se contar com previsões quanti- 
tativas com realismo crescente ( $\overline{\mathrm{LAW}}, 2007)$. A melhora pode ser percebida em termos de possibilidade de aumento no número possível de pontos de malha em cálculos de programas de Dinâmica de Fluidos Computacional (CFD), ou ainda na possibilidade de se aumentar o número de espécies químicas em modelos cinéticos, ou na resolução espacial de simulações numéricas diretas (DNS) de escoamentos turbulentos, por exemplo WESTBROOK et al. (2005). No entanto, enquanto o otimismo é justificado, deve-se ter um certo cuidado. Houve em anos recentes uma proliferação de mecanismos cinéticos bem como um esforço crescente em incorporá-los às simulações. Porém, por esses mecanismos serem aplicáveis de forma restrita, o seu uso indiscriminado pode facilmente levar a resultados incorretos de previsão, em combustão (LAW, 2007).

Como resultado há uma dependência - do êxito do processo de simulação dos mecanismos cinéticos selecionados bem como das condições individuais de chama (por exemplo, temperatura e pressão inicial dos reagentes e a quantidade relativa dos reagentes), o que termina por tornar o processo de simulação muito suscetível à experiência do modelador no que tange à escolha dos mecanismos de reação pertinentes a uma dada condição de trabalho, i.e. da escolha das reações fundamentais que regem a "dinâmica" do processo reativo.

Para demonstrar a importância de se escolher mecanismos abrangentes, e os efeitos nocivos de se desconsiderar componentes chave em um mecanismo, a figura 1.2 mostra, de forma exagerada ${ }^{3}$ o atraso calculado em tempo de autoignição de misturas heptano-ar obtidos utilizando-se dois mecanismos diferentes. Utilizando um mecanismo curto (HELD; MARCHESE; DRYER, 1997), especialmente desenvolvido para estudo de chamas (e como tal, em modelos conven-

\footnotetext{
${ }^{3}$ pois os mecanismos foram escolhidos de forma a ressaltar a importância de uma escolha meticulosa.
} 


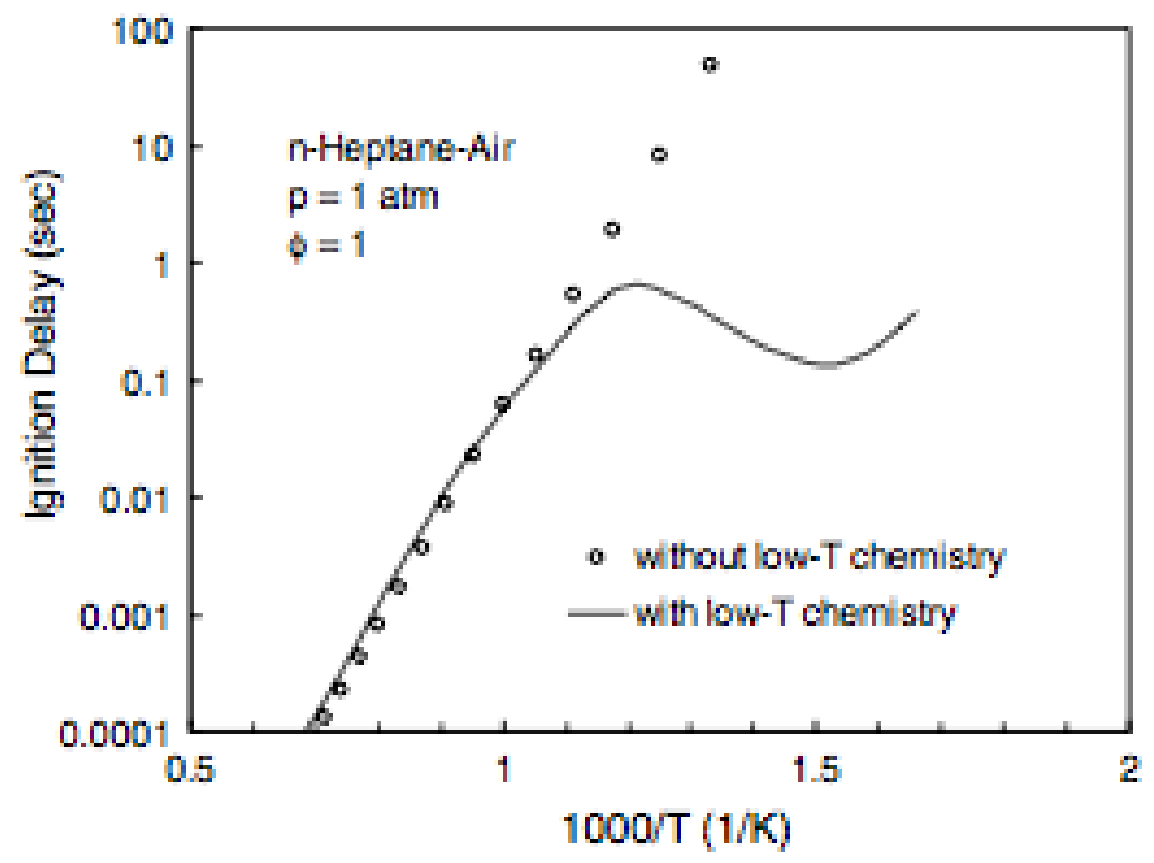

Figura 1.2: Atraso calculado no tempo de ignição de misturas de heptano-ar utilizando esquemas cinéticos com (CURRAN et al., 1998) e sem (HELD; MARCHESE; DRYER, 1997) mecanismos de baixa temperatura, mostrando a importância do comportamento de coeficiente negativo de temperatura.

cionais, não inclui a química de baixa temperatura responsável pelo coeficiente negativo de temperatura) e uma mecanismo mais detalhado, que inclui a química de baixa temperatura (< 850K) (CURRAN et al., 1998), vê-se que enquanto os dois mecanismos são equivalentes a altas temperaturas, eles diferem substancialmente e qualitativamente no regime de baixas temperaturas. Isso demonstra que enquanto um mecanismo pode fornecer resultados satisfatórios para uma classe de fenômenos, ou sob uma faixa estreita de condições termodinâmicas, ele pode ser totalmente inútil do ponto de vista físico, sob outras condições (LAW), 2007)

\footnotetext{
${ }^{4}$ ver-se-á que no modelo de chama apresentado não há distinção entre fenômenos que ocorrem a baixas ou a altas temperaturas.
} 
Em modelos cinético-químicos, ter-se um mecanismo abrangente é apenas um primeiro passo para se alcançar a previsibilidade quantitativa que não imponha custo computacional excessivo em um software de dinâmica dos fluidos computacional. Em escoamentos turbulentos e reativos, onde de forma simultânea precisa-se resolver um campo de velocidades flutuando rapidamente e com um alto grau de escalas espaciais (LAW, 2007), essa restrição se faz premente.

Embora o crescimento projetado da capacidade de computação tenda a aumentar, não é realista se esperar que mecanismos cinéticos detalhados de cadeias grandes de hidrocarbonetos sejam incorporados a programas de dinâmica dos fluidos computacional de forma indiscriminada (LAW, 2007).

A figura 1.3 mostra que em métodos cinéticos, estes mecanismos contêm de dezenas a centenas de espécies e de centenas a milhares de reações, com o mecanismo crescendo com o tamanho da molécula de combustível. Nesses métodos, a eliminação de algumas espécies leva à eliminação de um certo número de reações devido à relação linear entre o número de reações e o número de espécies, coisa que não é crítica no caso de um modelo químico-termodinâmico.

O tempo computacional necessário para a implementação de modelos cinéticos em simulação de chama turbulenta - até os mais simples - e a rigidez numérica $^{5}$ das equações diferenciais presentes inviabilizam o seu uso indiscriminado em códigos computacionais de simulação com aplicação industriais, restringindo

\footnotetext{
${ }^{5}$ as equações que envolvem as espécies nas reações químicas presentes nos mecanismos são acopladas e têm tempos em escalas características muito diferentes - dando origem à "rigidez" pois os incrementos de tempo, se resolvidas de forma convencional devem ser pequenos, mesmo para aquelas equações que não demandam incrementos pequenos, fazendo com que o sistema como um todo avance de forma lenta - e as técnicas de solução usadas nesse tipo de sistema para evitar esse fato são bem específicas (WESTBROOK; DRYER, 1984).
} 


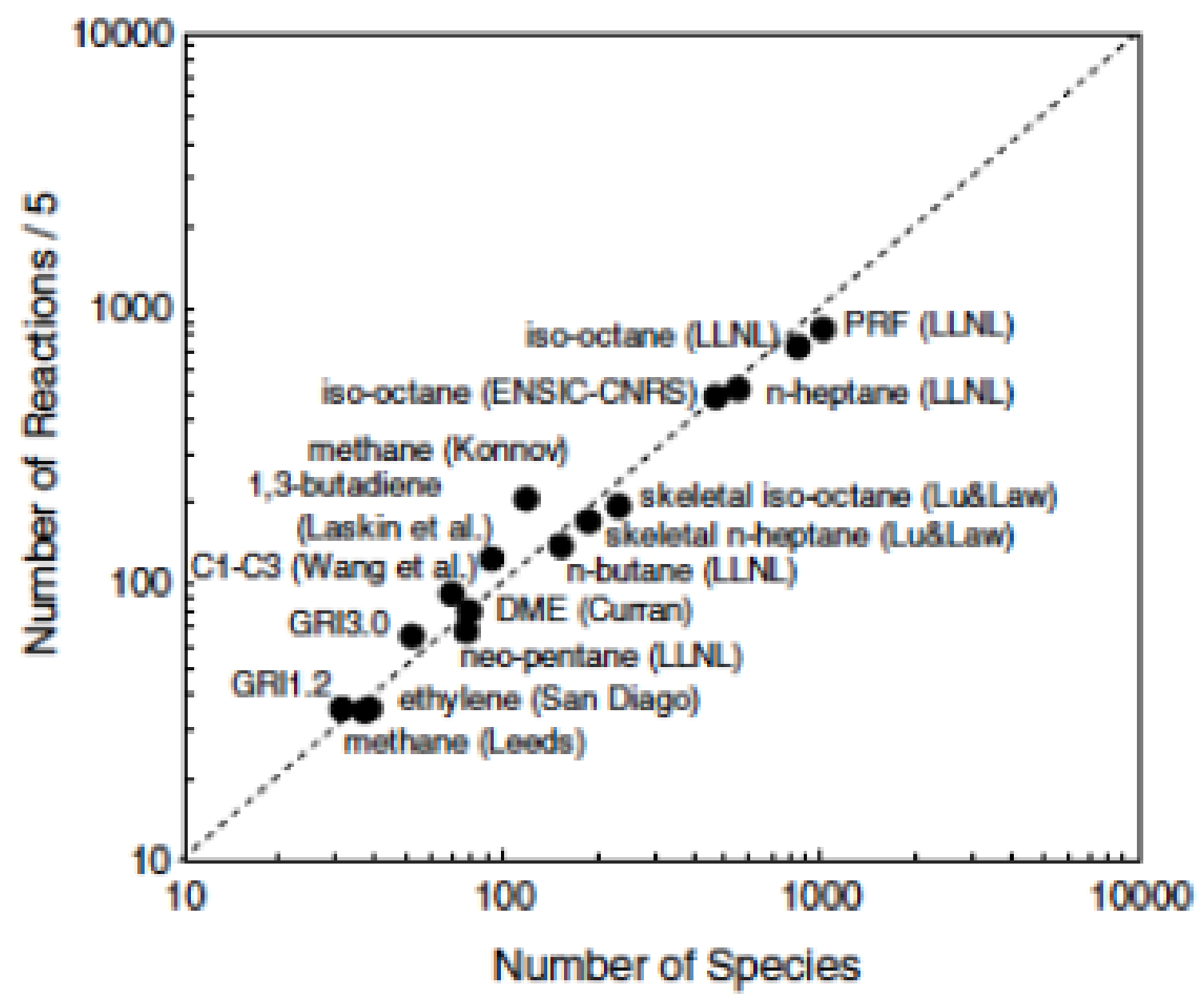

Figura 1.3: Compilação do número de reações em função do número de espécies para mecanismos de hidrocarbonetos $\mathrm{C} 1-\mathrm{C} 8$, mostrando uma relação aproximadamente linear, extraído de (LAW, 2007) 
o campo de aplicação dessa ferramenta, que, em muitos casos, se serve, de cinéticas reduzidas (no extremo, de cinéticas de um ou dois passos, como as de JONES; LINDSTEDT (1988) e WESTBROOK; DRYER (1984)), restringindo significativamente a possibilidade de previsão de emissões, que passam a depender de "ajustes" dos coeficientes dos "mecanismos" de reação envolvidos.

A previsão de poluentes em chamas turbulentas é um dos campos em que essa restrição se faz mais sentir e embora o esforço empreendido em pesquisa seja grande, há uma enorme lacuna entre o que se necessita em códigos de simulação de dinâmica dos fluidos de chamas industriais e o que os esquemas menos completos de reação conseguem a eles oferecer, limitando a eficácia de sua utilização e justificando maior esforço em pesquisa, inclusive por motivo de legislação cada vez mais restritiva no que concerne as emissões de poluentes com os óxidos de nitrogênio $\left(N O_{x}\right)$, monóxido de carbono $(C O)$ e hidrocarbonetos não queimados, que via de regra limitam o uso de combustíveis de menor valor.

Em chamas de pré-mistura, como as que serão tratadas aqui, por estarem os reagentes previamente misturados, o processo de reação é limitante, em contraposição a chamas não pré-misturadas, onde o processo fluido-dinâmico de mistura pode ser limitante. A compreensão do processo reativo se torna, por esse motivo, fundamental para o entendimento da dinâmica de chama de pré-mistura.

Tentativas de simulação de chama utilizando-se de conceitos de equilíbrio químico em fase univocamente definida (uma e única fase), por exemplo, embora tenham tido êxito em simular a propagação de chama e o desenvolvimento da pressão em cilindro no caso de motor de combustão interna, resultaram, sistematicamente, em previsões de emissões que não condizem com a realidade (VERHELST; SHEPPARD, 2009). As frações molares de espécies previstas, mesmo algumas majoritárias, tendem a super-dimensionar (viz. frozen equili- 
brium ${ }^{6}$ os resultados de medições experimentais, restringindo o uso, para este fim, desse tipo de modelo.

Ao considerar, inicialmente, a chama como sendo um fenômeno multifásico e bivariante, a presente abordagem almeja restabelecer a viabilidade de um enfoque de equilíbrio: termodinâmico.

Ao procurar desconstruir a chama, tenta resgatar o que pode vir a ser um núcleo em equilíbrio químico a partir do qual poder-se-á, então, tentar reconstruir a chama real, permitindo uma compreensão mais fundamental desse fenômeno.

\subsection{Motivação}

Chamas de pré-mistura parecem ter semelhanças com a Criticalidade Autoorganizada ( $\mathrm{CAo}$ ). Sistemas desse tipo têm muitos graus de liberdade. Como decorrência, sistemas em que o que se convencionou denominar de equilíbrio puntuado, como em ELDREDGE; GOULD (1972) e BAK (1996), estão presentes, sendo estes predominantes em sistemas abertos, ver figura 1.4. Esta figura mostra uma representação pictórica do equilíbrio puntuado. Especificamente, tem-se um modelo de evolução: o eixo ordenado mostra a atividade acumulada, ou seja as mutações acumuladas para uma espécie em função do tempo. Podese imaginar que na ordenada se tenha a quantidade de mudança física, com o tempo. Percebe-se que há longos períodos sem atividades, separados por mudanças repentinas de atividade. Entre cada degrau há infinitamente mais degraus,

\footnotetext{
${ }^{6}$ nesta condição, alguns produtos de combustão gerados a altas temperaturas têm, por causa de um mecanismo cinético muito dependente da temperatura, suas frações molares de equilíbrio "congeladas", pela rápida redução de temperatura fora da câmara de combustão.
} 
resultado da invariância de escala. Em uma chama poderíamos imaginar o eixo das ordenadas como sendo o da temperatura e o das abscissas como sendo 0 progresso da reação.

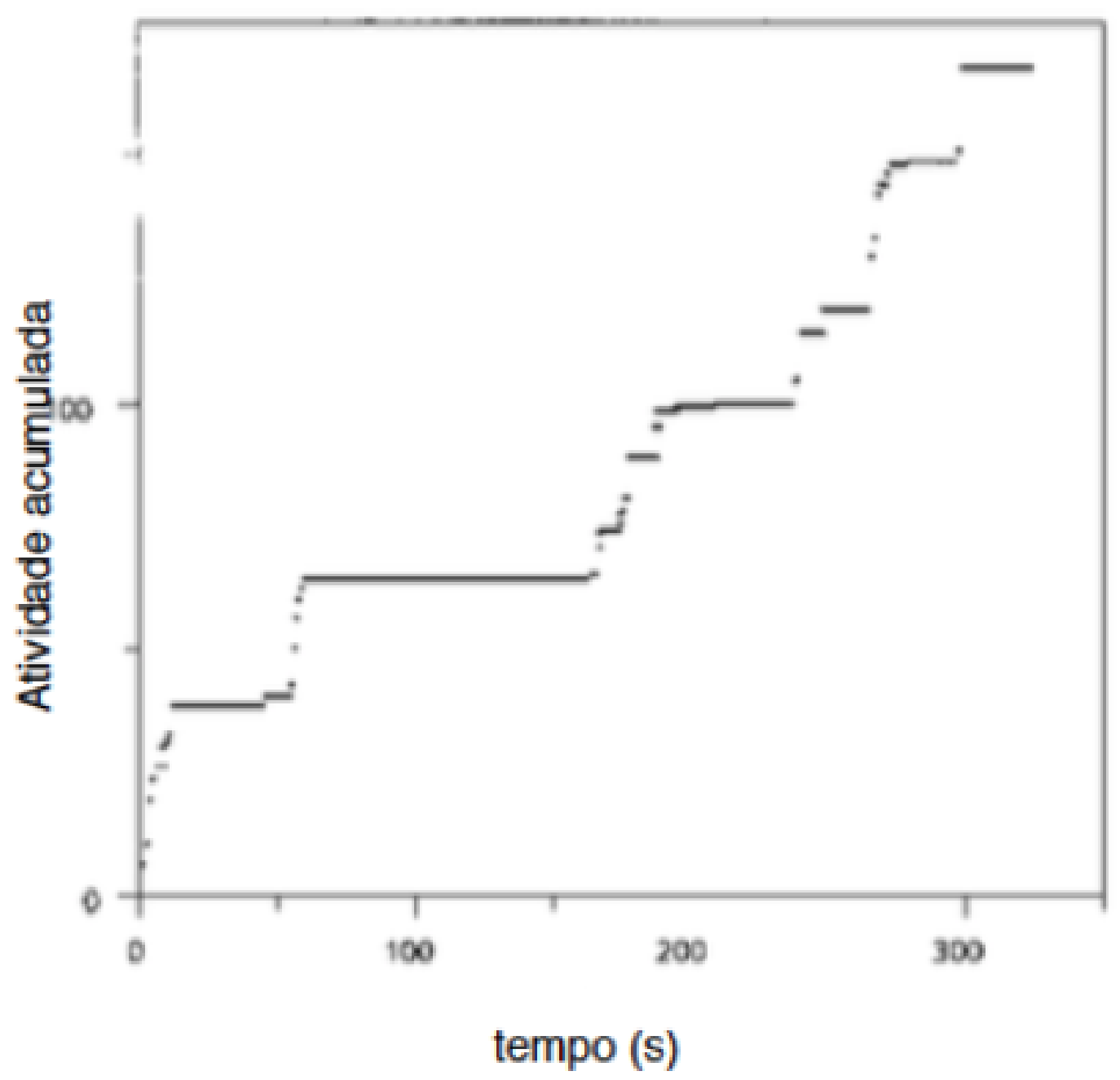

Figura 1.4: Representação pictórica do equilíbrio puntuado (BAK, 1996)

Neles, a progressão de um estado a outro é caracterizada por saltos abruptos, 
resultando em descontinuidade de suas propriedades. Ao contrário dos estados críticos atingidos na termodinâmica de equilíbrio, onde há necessidade de se ajustar os parâmetros do sistema para que o estado crítico seja atingido, na CAo os pontos críticos são atingidos através da auto-organização. Tem-se uma estrutura, que é atraída até o ponto crítico, onde ocorre uma transição de fase contínua e se forma uma nova estrutura. No ponto crítico dos sistemas de CAo, o sistema tem propriedades semelhantes à de um sistema termodinâmico em equilíbrio perto de uma transição de fase de segunda ordem.

Segundo BAK (1996):

"[...] o comportamento complexo na Natureza reflete a tendência de sistemas grandes com muitos componentes de evoluirem para um estado "crítico", fora do equilíbrio, onde perturbações mínimas podem levar a eventos denominados de avalanches, de todos os tamanhos. A maioria dos eventos se dá através de mudanças catastróficas ao invés de mudanças suaves, sem a intervenção de nenhum agente externo. Este estado é atingido exclusivamente pelas interações entre os elementos individuais do sistema: o estado crítico é auto-organizado. A CAo é até o momento o único mecanismo geral para criar complexidade."7 7

Os fenômenos descritos pela ciência da CAo são estacionários e se mostram invariantes em escala. São representados por leis de potência; leis em que o número de fenômenos $N(s)$ e o tamanho dos fenômenos $(s)$, por exemplo, se relacionam através de um expoente $(\tau)$;

$$
N(s)=s^{-\tau}
$$

\footnotetext{
${ }^{7}$ sistemas complexos são aqueles em que as partes interagem de forma a apresentar estruturas variadas e que têm comportamento diferente que o da soma das partes p.ex. ecossitemas.
} 
A invariância de escala pode ser observada pelo fato que a reta gerada pelo gráfico bi- $\log \log N(s) \times \log s$ ter o mesmo aspecto em qualquer posição, ver figura 1.5, BAK (1996).

As partes de um sistema crítico não podem ser compreendidas isoladamente. A dinâmica observada localmente reflete o fato de que ela é parte integrante do sistema todo (BAK, 1996), portanto, abordagens reducionistas não são apropriadas. O uso de princípios de otimização nesses casos pode ser uma alternativa.

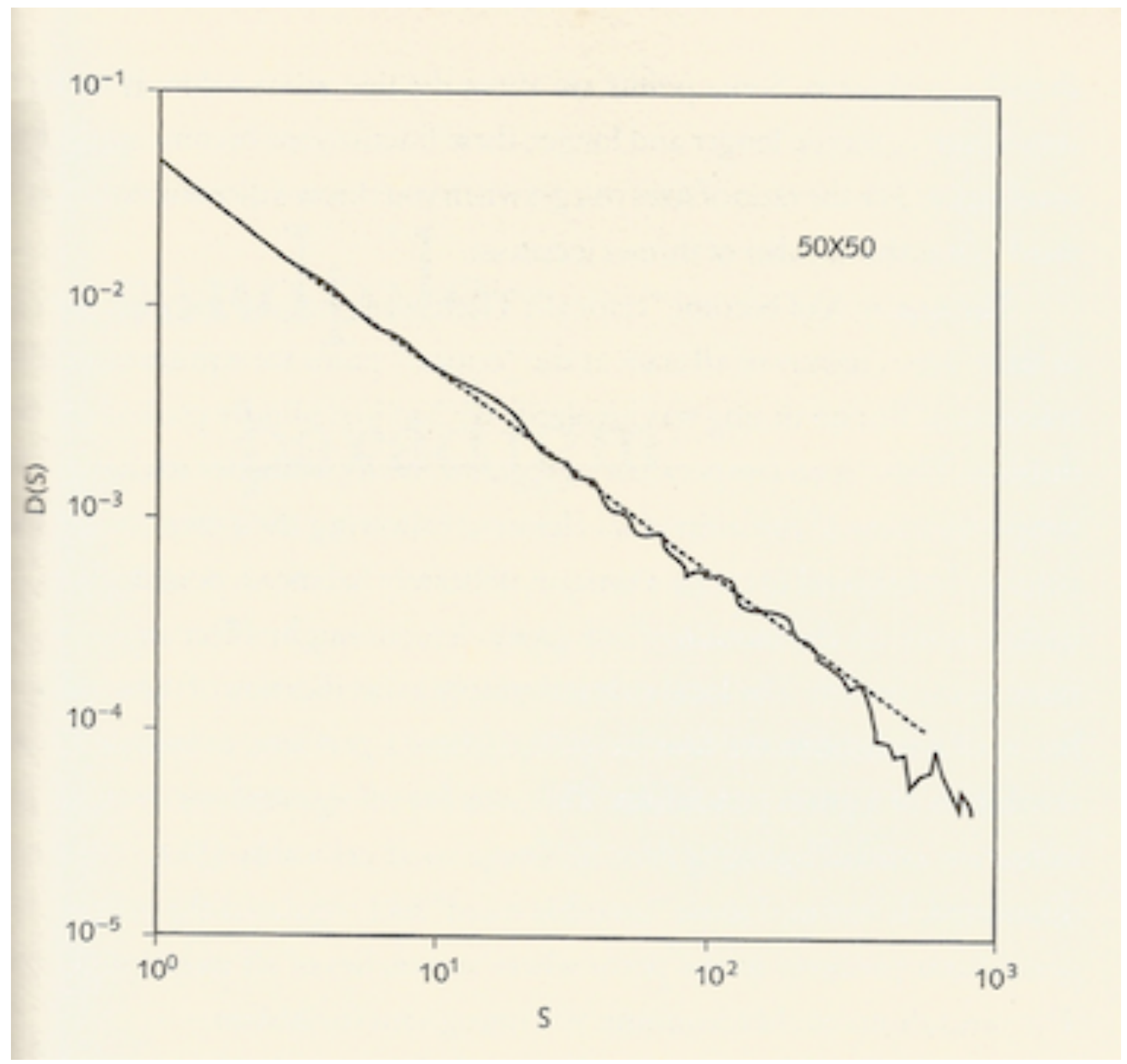

Figura 1.5: Representação da Lei de Potência para uma distribuição de avalanches, por tamanho, em um modelo de montes de areia (BAK, 1996) 
Embora seja uma teoria explicativa, a CAo é utilizada para estudar fenômenos tão diversos como avalanches, incêndios em floresta e congestionamentos de trânsito, por exemplo, sempre do ponto de vista qualitativo. A CAo é pautada por descrições na maior parte dos casos fenomenológica e neste espaço procurarse-á, com o auxílio da análise exergética, fazer uma investigação também de caráter preditivo, podendo esta oferecer insights de como se dá a mecânica de uma transformação como a que ocorre em chamas de pré-mistura.

De importância tecnológica a possibilidade de se poder vir a obter êxito em simular, com auxílio da termodinâmica, por exemplo, as emissões em chamas laminares, e de se poder incorporar sub-modelos reativos em simuladores de Dinâmica dos Fluidos Computacional, já que se conseguiria substancial economia de recursos computacionais de simulação, pois as equações diferenciais rígidas (e de difícil convergência), com dependência temporal de amplo espectro, utilizadas na simulação cinética seriam substituídas por equações, em sua maior parte, algébricas lineares ou de não-linearidade reduzida.

Além disso, um modelo termodinâmico abriria um campo para que, em se tendo uma simulação de poluentes, em chamas turbulentas, menos suscetível à experiência do usuário de software de simulação, e permitir ainda a evolução de projeto de equipamentos industriais segundo necessidades de legislação que teria, nesse horizonte, também espaço para evoluir.

É conveniente que se pergunte:

É possível um estudo mais fundamental de CAo, com caráter preditivo? Existe uma relação entre ela e a Termodinâmica? 


\section{Capítulo 2}

\section{Objetivos}

\subsection{Objetivo Geral}

Obterem-se elementos para que se possa efetuar a modelagem termodinâmica de chamas de pré-mistura em escoamento ideal utilizando-se princípios de otimização.

\subsection{Objetivos Específicos}

- pretende-se elaborar um princípio de otimização para uma chama de duas fatias que possa ser replicado em chamas de " $n$ " fatias.

- pretende-se retirar a condição de "caixa preta" do sistema termodinâmico que se tem quando se utiliza a análise exergética, substituindo-se a referência externa por uma referência interna apropriada. 
- pretende-se formular a chama adiabática reversível de duas fatias, onde ocorre a transformação de exergia química em exergia térmica.

- pretende-se mostrar que a chama contínua não é o limite da chama de infinitas fatias;

o pretende-se mostrar que, para este modelo, a condição de trabalho perdido é distinta da condição da entropia gerada, o que não fica evidente quando se utiliza o ambiente como referência. 


\section{Capítulo 3}

\section{A modelagem termodinâmica}

\section{de chamas: revisão bibliográfica}

\subsection{Introdução}

A classificação de chamas pode se dar em função do regime de escoamento dos reagentes e do grau de mistura entre o oxidante e o combustível, WARNATZ; MAAS; DIBBLE (2006). Seguindo esses critérios, tem-se:

Chamas industriais são invariavelmente turbulentas, e na maior parte das vezes de não pré-mistura. Por motivos de segurança - para não haver risco de explosão

Tabela 3.1: Tipos de Chamas

\begin{tabular}{l|l|l} 
Classificação de Chamas & Escoamento Laminar & Escoamento Turbulento \\
\hline Reagentes Misturados & Laminar de Pré-Mistura & Turbulenta de Pré-Mistura \\
\hline Reagentes Separados & Laminar de não Pré-Mistura & Turbulenta de não Pré-Mistura
\end{tabular}


- os reagentes entram na câmara de combustão separados entre si (embora haja exceções notáveis - como em motores de combustão interna de ciclo Otto).

Em chamas de não pré-mistura, o processo fluido-dinâmico de mistura entre os reagentes é limitante para o processo de combustão (mixed is burnt - limite fluidodinâmico), enquanto que em chamas de pré-mistura, por estarem os reagentes previamente misturados, o limitante para que ocorra combustão completa se dá pela velocidade com que ocorrem as transformações reativas (limite cinéticoquímico). Serão estas as chamas objeto deste estudo.

\subsection{Modelagem de Chamas de Pré-Mistura}

Historicamente, a modelagem de chamas de pré-mistura tem sido feita por meio da escolha de mecanismos de reação, que, depois de eleitos, quantificam cada espécie dentre as presentes, através da resolução de equações diferenciais que incorporam a cinética envolvida bem como a advecção e o transporte em forma de difusão, de espécies. Por se acreditar que chamas são fenômenos que ocorrem distante da condição de equilíbrio (GAYDON; WOLFHARD, 1970), esta tem sido a abordagem clássica ou de referência. A hipótese subjacente é a de que se faz necessário efetuar análises de não equilíbrio como essas, pois acredita-se, a termodinâmica não se aplica.

Em simulações computacionais de modelos cinéticos de chamas de pré-mistura unidimensionais a baixas pressões, normalmente se utiliza, para esse cálculo, a hipótese de escoamento com baixo número de Mach e um perfil de temperaturas pré-determinado, medido experimentalmente - pois a maioria desses modelos não prevê a possibilidade de troca de calor substancial que pode ocorrer entre 
chamas reais e o ambiente, o que geraria uma alteração no perfil de temperatura em relação ao esperado em modelos adiabáticos unidimensionais de que esses simuladores se utilizam (por exemplo o PREMIX, criado por Sandia Laboratories -(KEE; RUPLEY; MILLER, 1987)) e que poderia ter consequências importantes quando da comparação com dados experimentais.

Além disso, por exemplo, hipóteses não triviais são adotadas referentes aos processos de transporte molecular, onde o coeficiente de difusividade de todas as espécies é tido como sendo o mesmo. Os efeitos Soret ${ }^{1}$ e Dufour ${ }^{2}$ são desprezados e o número de Lewis é tido como sendo constante 3 .

Finalmente, hipóteses referentes à forma de taxa de reação e de como a massa específica e a difusividade variam em função de temperatura e concentração de espécies químicas devem ser criteriosamente definidas.

Em sua maioria, teorias de chamas laminares de pré-mistura, substituem o complexo de reações químicas com numerosa quantidade de espécies - a maioria intermediárias - por cinéticas globais, i.e. uma única reação ou reação de passo único (POPE, 1987). CLAVIN (1985) corrobora esta hipótese simplificadora, que não é satisfatória, segundo ele entretanto, para descrever fenômenos como a extinção, formação de poluentes e resposta de reações ao uso de aditivos. Além disso, um mecanismo global não é, em geral, adequado à descrição de ignição.

Em chamas de hidrogênio com oxigênio, como as que se pretende modelar, há

\footnotetext{
1é a ocorrência de um fluxo difusivo devido a um gradiente de temperatura.

2é o recíproco do efeito Soret; a ocorrência de um fluxo de calor devido a um gradiente de potencial químico.

${ }^{3} L e=\frac{\nu}{D}$; onde Le é o número de Lewis, $\nu$ é igual à difusividade térmica e $D$ é igual à difusividade de massa.
} 
tipicamente até 8 espécies químicas intermediárias presentes:

$$
\mathrm{H}_{2}, \mathrm{O}_{2}, \mathrm{H}, \mathrm{O}, \mathrm{OH}, \mathrm{HO}_{2}, \mathrm{H}_{2} \mathrm{O}_{2}, \mathrm{H}_{2} \mathrm{O}
$$

e mecanismos de até 20 reações, por exemplo, CONAIRE et al. (2004), não são incomuns (ver tabela 3.2). Nessa tabela tem-se uma listagem de um passo a passo das principais reações elementares que compõem a oxidação do hidrogênio com o oxigênio (i.e um possível mecanismo). Segundo os autores, as constantes de velocidade de reação são apresentadas levando em conta a sua incerteza (uncertainty factor UF). As simulações feitas usando desse mecanismo correspondem a:

"[. . . ] experimentos de ignição cobrem temperaturas que variam de $950 \mathrm{~K}$ a $2700 \mathrm{~K}$ e de pressões subatmosféricas até pressões de 87atm; oxidação de hidrogênio em reatores de fluxo a temperaturas em torno de $900 \mathrm{~K}$, de 0.3 até $15.7 \mathrm{~atm}$; velocidades de chama de hidrogênio-oxigênio-inertes de 0.35 a 4 atm; e estrutura de chama de hidrogênio de 1 a 10 atm."

As simulações usando esse mecanismo são validadas em maior ou menor grau com os experimentos. Segundo os autores, ainda, os mecanismos de reação apresentados por autores diferentes diferem no número de reações e nas constantes de reação. Os autores enfatizam a importância da necessidade de análise do mecanismo para que se tenha uma exaustiva lista de reações.

Enquanto, segundo GARDINER (2000), as reações de importância da oxidação do $H_{2}$ seriam conhecidas, publicações de alguns aspectos desse mecanismo continuam a aparecer. KONNOV (2008), por exemplo, cita as incertezas em mecanismo de oxidação de $\mathrm{H}_{2}$. Essa reação de oxidação já foi estudada a várias temperaturas, pressões e composições. Prosseguem, no entanto, refinamentos como escolha de mecanismos alternativos e ajuste de coeficientes. 
A possibilidade de se modificar mecanismos através de escolha alternativa de reações componentes desses mesmos mecanismos e de se alterar as constantes de velocidade de reações é consequência do alto grau de indeterminação do mecanismo cinético-químico "final". Isso resulta indefinição das quantidades relativas das espécies envolvidas e se constitui em importante lacuna desse tipo de paradigma. Estas questões são de difícil resolução, por se poder eleger, para diferentes mecanismos e diferentes regimes de combustão, mecanismos "ótimos" alternativos. Quanto maior o número de espécies intermediárias, maior a instabilidade metodológica, por conseguinte. 
Tabela 3.2: Parte do mecanismo de oxidação de $H_{2}$ com $\mathrm{O}_{2}$, extraído de (KONNOV, 2008)

H/O kinetic mechanism: units are $\mathrm{cm}^{3} \mathrm{mols} \mathrm{sal} \mathrm{K,} k=A T^{n} \exp \left(-E_{\mathrm{a}} / R T\right), \mathrm{UF}=$ uncertainty factor

\begin{tabular}{|c|c|c|c|c|c|c|}
\hline No. & Reaction & A & $n$ & $E_{\mathrm{a}}$ & Temperatures & UF \\
\hline \multirow[t]{2}{*}{ 1a } & $\begin{array}{l}\mathrm{H}+\mathrm{H}+\mathrm{M}=\mathrm{H}_{2}+\mathrm{M}^{\mathrm{a}} \\
\text { Enhanced third-body efficiencies (relativ }\end{array}$ & $\begin{array}{l}7.00 \mathrm{E}+17 \\
\text { to } \mathrm{Ar})\end{array}$ & -1.0 & 0 & $77-5000$ & 2 \\
\hline & $\mathrm{H}_{2}=0, \mathrm{~N}_{2}=0, \mathrm{H}=0, \mathrm{H}_{2} \mathrm{O}=14.3$ & & & & $300-2000$ & 5 \\
\hline $1 \mathrm{~b}$ & $\mathrm{H}+\mathrm{H}+\mathrm{H}_{2}=\mathrm{H}_{2}+\mathrm{H}_{2}$ & $1.00 \mathrm{E}+17$ & -0.6 & 0 & $50-5000$ & 2.5 \\
\hline $1 \mathrm{c}$ & $\mathrm{H}+\mathrm{H}+\mathrm{N}_{2}=\mathrm{H}_{2}+\mathrm{N}_{2}$ & $5.40 \mathrm{E}+18$ & -1.3 & 0 & $77-2000$ & 3.2 \\
\hline 1d & $\mathrm{H}+\mathrm{H}+\mathrm{H}=\mathrm{H}_{2}+\mathrm{H}$ & $3.20 \mathrm{E}+15$ & 0 & 0 & $50-5000$ & 3.2 \\
\hline \multirow[t]{2}{*}{2} & $\mathrm{O}+\mathrm{O}+\mathrm{M}=\mathrm{O}_{2}+\mathrm{M}^{\mathrm{a}}$ & $1.00 \mathrm{E}+17$ & -1.0 & 0 & $300-5000$ & 2 \\
\hline & $\begin{array}{l}\text { Enhanced third-body efficiencies (relativ } \\
\mathrm{O}=28.8, \mathrm{O}_{2}=8, \mathrm{NO}=2, \mathrm{~N}=2, \mathrm{~N}_{2}= \\
\mathrm{H}_{2} \mathrm{O}=5\end{array}$ & $\begin{array}{l}\text { to } \mathrm{Ar}) \\
2\end{array}$ & & & & $\begin{array}{l}2 \\
3\end{array}$ \\
\hline 3 & $\begin{array}{l}\mathrm{O}+\mathrm{H}+\mathrm{M}=\mathrm{OH}+\mathrm{M}^{\mathrm{a}} \\
\text { Enhanced third-body efficiency: } \\
\mathrm{H}_{2} \mathrm{O}=5\end{array}$ & $6.75 \mathrm{E}+18$ & -1.0 & 0 & $2950-3700$ & 3 \\
\hline \multirow[t]{2}{*}{$4 \mathrm{a}$} & $\mathrm{H}_{2} \mathrm{O}+\mathrm{M}=\mathrm{H}+\mathrm{OH}+\mathrm{M}^{\mathrm{a}}$ & $6.06 \mathrm{E}+27$ & -3.312 & 120,770 & $300-3400$ & 2 \\
\hline & $\begin{array}{l}\text { Enhanced third-body efficiencies (relativ } \\
\mathrm{H}_{2} \mathrm{O}=0, \mathrm{H}_{2}=3, \mathrm{~N}_{2}=2, \mathrm{O}_{2}=1.5\end{array}$ & to $\mathrm{Ar})$ & & & & \\
\hline $4 \mathrm{~b}$ & $\mathrm{H}_{2} \mathrm{O}+\mathrm{H}_{2} \mathrm{O}=\mathrm{H}+\mathrm{OH}+\mathrm{H}_{2} \mathrm{O}$ & $1.00 \mathrm{E}+26$ & -2.44 & 120,160 & $300-3400$ & 2 \\
\hline \multirow[t]{2}{*}{$5 a$} & $\mathrm{H}+\mathrm{O}_{2}(+\mathrm{M})=\mathrm{HO}_{2}(+\mathrm{M})^{\mathrm{a}, \mathrm{b}}$ & $4.66 \mathrm{E}+12$ & 0.44 & 0 & $300-2000$ & 1.2 \\
\hline & $\begin{array}{l}\text { Low-pressure limit: } \\
F_{\text {cent }}=0.5 \\
\text { Enhanced third-body efficiencies (relativ }\end{array}$ & $\begin{array}{l}5.70 \mathrm{E}+19 \\
\text { to } \mathrm{N}_{2} \text { ): } \\
=0.57\end{array}$ & -1.4 & 0 & $300-2000$ & \\
\hline \multirow[t]{2}{*}{$5 \mathrm{~b}$} & $\begin{array}{l}\left.\mathrm{Ar}=\mathrm{H}_{2} \mathrm{H}=0, \mathrm{O}_{2}=0, \mathrm{H}_{2}=\mathrm{Ar}\right)=\mathrm{HO}_{2}(+\mathrm{Ar})^{\mathrm{b}} \\
\mathrm{H}+\mathrm{O}_{2}(+\mathrm{Hr} \text {. }\end{array}$ & $4.66 \mathrm{E}+12$ & 0.44 & 0 & $300-2000$ & 1.2 \\
\hline & $F_{\text {cent }}=0.5$ & & & & & \\
\hline \multirow[t]{2}{*}{$5 c$} & $\mathrm{H}+\mathrm{O}_{2}\left(+\mathrm{O}_{2}\right)=\mathrm{HO}_{2}\left(+\mathrm{O}_{2}\right)^{\mathrm{b}}$ & $4.66 \mathrm{E}+12$ & 0.44 & 0 & $300-2000$ & 1.2 \\
\hline & $\begin{array}{l}\text { Low-pressure limit: } \\
F_{\text {cent }}=0.5\end{array}$ & $5.69 \mathrm{E}+18$ & -1.094 & 0 & $300-700$ & 1.3 \\
\hline $5 d$ & $\begin{array}{l}\mathrm{H}+\mathrm{O}_{2}\left(+\mathrm{H}_{2} \mathrm{O}\right)=\mathrm{HO}_{2}\left(+\mathrm{H}_{2} \mathrm{O}\right)^{\mathrm{b}} \\
\text { Low-pressure limit: } \\
F_{\text {cent }}=0.8\end{array}$ & $\begin{array}{l}9.06 \mathrm{E}+12 \\
3.67 \mathrm{E}+19\end{array}$ & $\begin{array}{r}0.2 \\
-1.0\end{array}$ & $\begin{array}{l}0 \\
0\end{array}$ & $\begin{array}{l}1050-1250 \\
1050-1250\end{array}$ & 1.4 \\
\hline 6a & $\begin{array}{l}\mathrm{OH}+\mathrm{OH}(+\mathrm{M})=\mathrm{H}_{2} \mathrm{O}_{2}(+\mathrm{M})^{\mathrm{a}, \mathrm{b}} \\
\text { Low-pressure limit: } \\
F_{\text {cent }}=0.5 \\
\text { Enhanced third-body efficiency: } \\
\mathrm{H}_{2} \mathrm{O}=0\end{array}$ & $\begin{array}{l}1.00 \mathrm{E}+14 \\
2.38 \mathrm{E}+19\end{array}$ & $\begin{array}{l}-0.37 \\
-0.8\end{array}$ & $\begin{array}{l}0 \\
0\end{array}$ & $\begin{array}{l}200-1500 \\
250-1400\end{array}$ & $\begin{array}{l}2.5 \\
2.5\end{array}$ \\
\hline $6 \mathrm{~b}$ & $\begin{array}{l}\mathrm{OH}+\mathrm{OH}\left(+\mathrm{H}_{2} \mathrm{O}\right)=\mathrm{H}_{2} \mathrm{O}_{2}\left(+\mathrm{H}_{2} \mathrm{O}\right)^{\mathrm{b}} \\
\text { Low-pressure limit: } \\
F_{\text {cent }}=0.5\end{array}$ & $\begin{array}{l}1.00 \mathrm{E}+14 \\
1.45 \mathrm{E}+18\end{array}$ & $\begin{array}{c}-0.37 \\
0\end{array}$ & $\begin{array}{l}0 \\
0\end{array}$ & $\begin{array}{l}200-1500 \\
300-400\end{array}$ & $\begin{array}{l}2.5 \\
2.5\end{array}$ \\
\hline 7 & $\mathrm{O}+\mathrm{H}_{2}=\mathrm{OH}+\mathrm{H}$ & $5.06 \mathrm{E}+04$ & 2.67 & 6290 & $297-2495$ & 1.3 \\
\hline 8 & $\mathrm{H}+\mathrm{O}_{2}=\mathrm{OH}+\mathrm{O}$ & $2.06 \mathrm{E}+14$ & -0.097 & 15,022 & $800-3500$ & 1.5 \\
\hline 9 & $\mathrm{H}_{2}+\mathrm{OH}=\mathrm{H}_{2} \mathrm{O}+\mathrm{H}$ & $2.14 \mathrm{E}+08$ & 1.52 & 3450 & $300-2500$ & 2 \\
\hline 10 & $\mathrm{OH}+\mathrm{OH}=\mathrm{H}_{2} \mathrm{O}+\mathrm{O}$ & $3.34 \mathrm{E}+04$ & 2.42 & -1930 & $250-2400$ & 1.5 \\
\hline 11 & $\mathrm{HO}_{2}+\mathrm{O}=\mathrm{OH}+\mathrm{O}_{2}$ & $1.63 \mathrm{E}+13$ & 0 & -445 & $220-400$ & 1.2 \\
\hline 12 & $\mathrm{H}+\mathrm{HO}_{2}=\mathrm{OH}+\mathrm{OH}$ & $1.90 \mathrm{E}+14$ & 0 & 875 & $300-1000$ & 2 \\
\hline 13 & $\mathrm{H}+\mathrm{HO}_{2}=\mathrm{H}_{2} \mathrm{O}+\mathrm{O}$ & $1.45 \mathrm{E}+12$ & 0 & 0 & 300 & 3 \\
\hline 14 & $\mathrm{H}+\mathrm{HO}_{2}=\mathrm{H}_{2}+\mathrm{O}_{2}$ & $1.05 \mathrm{E}+14$ & 0 & 2047 & $250-1000$ & 2 \\
\hline 15 & $\mathrm{H}_{2}+\mathrm{O}_{2}=\mathrm{OH}+\mathrm{OH}$ & $2.04 \mathrm{E}+12$ & 0.44 & 69,155 & $298-1000$ & 3 \\
\hline 16 & $\mathrm{HO}_{2}+\mathrm{OH}=\mathrm{H}_{2} \mathrm{O}+\mathrm{O}_{2}{ }^{\mathrm{c}}$ & $\begin{array}{l}2.89 \mathrm{E}+13 \\
+9.27 \mathrm{E}+15\end{array}$ & $\begin{array}{l}0 \\
0\end{array}$ & $\begin{array}{l}-500 \\
17,500\end{array}$ & $250-2000$ & $\begin{array}{l}3 \\
3\end{array}$ \\
\hline $17 \mathrm{a}$ & $\mathrm{HO}_{2}+\mathrm{HO}_{2}=\mathrm{H}_{2} \mathrm{O}_{2}+\mathrm{O}_{2}{ }^{\mathrm{c}}$ & $\begin{array}{l}1.03 \mathrm{E}+14 \\
+1.94 \mathrm{E}+11\end{array}$ & $\begin{array}{l}0 \\
0\end{array}$ & $\begin{array}{l}11,040 \\
-1409\end{array}$ & $300-1250$ & $\begin{array}{l}2.5 \\
1.4\end{array}$ \\
\hline $\begin{array}{l}17 \mathrm{~b} \\
18\end{array}$ & $\begin{array}{l}\mathrm{HO}_{2}+\mathrm{HO}_{2}+\mathrm{M}=\mathrm{H}_{2} \mathrm{O}_{2}+\mathrm{O}_{2}+\mathrm{M} \\
\mathrm{H}_{2} \mathrm{O}_{2}+\mathrm{H}=\mathrm{HO}_{2}+\mathrm{H}_{2}\end{array}$ & $\begin{array}{l}6.84 \mathrm{E}+14 \\
1.70 \mathrm{E}+12\end{array}$ & $\begin{array}{l}0 \\
0\end{array}$ & $\begin{array}{l}-1950 \\
3755\end{array}$ & $\begin{array}{l}230-420 \\
300-1000\end{array}$ & $\begin{array}{l}1.4 \\
3\end{array}$ \\
\hline 19 & $\mathrm{H}_{2} \mathrm{O}_{2}+\mathrm{H}=\mathrm{H}_{2} \mathrm{O}+\mathrm{OH}$ & $1.00 \mathrm{E}+13$ & 0 & 3575 & $300-1000$ & 2 \\
\hline 20 & $\mathrm{H}_{2} \mathrm{O}_{2}+\mathrm{O}=\mathrm{HO}_{2}+\mathrm{OH}$ & $9.55 \mathrm{E}+6$ & 2 & 3970 & $300-2500$ & 3 \\
\hline 21 & $\mathrm{H}_{2} \mathrm{O}_{2}+\mathrm{OH}=\mathrm{HO}_{2}+\mathrm{H}_{2} \mathrm{O}^{\mathrm{c}}$ & $\begin{array}{l}2.00 \mathrm{E}+12 \\
+1.70 \mathrm{E}+18\end{array}$ & $\begin{array}{l}0 \\
0\end{array}$ & $\begin{array}{l}427 \\
29,400\end{array}$ & $240-1700$ & 2 \\
\hline
\end{tabular}


Segundo CHESKIS (1999), enquanto o estado-da-arte da tecnologia de combustão - especialmente enquanto em busca de novas tecnologias que permitam atender às exigências mais rígidas com relação à quantidade de poluentes emitidos de equipamentos de combustão - exige uma melhoria (contínua) dos mecanismos químicos que descrevem o processo de combustão. $\mathrm{O}$ avanço em medição de perfis espaciais de espécies intermediárias permite prover, ainda, informações importantes em obtenção de um melhor entendimento de detalhes de mecanismos cinético-químicos.

As equações de conservação de espécies químicas, acopladas às equações de conservação (de massa, de quantidade de movimento e de energia, associadas ou não a modelos de turbulência, por exemplo), fornecem o campo de cada uma das respectivas grandezas envolvidas em modelo (temperatura, pressão, frações molares de espécies químicas presentes, velocidades de escoamento e suas flutuações).

\subsection{Modelagem termodinâmica de tempera- tura de chama adiabática}

Análises de natureza termodinâmica têm tido sucesso na determinação de temperaturas de chama adiabática, por exemplo, TABRIZI; SHARAK; SHARAK (2012), que utilizou, para isso, métodos de otimização não linear. Não há, no entanto, iniciativas de sucesso que resolvessem as espécies e temperaturas e pressões intermediárias de chama, com o uso exclusivo de termodinâmica. O cálculo de emissões - e para isso é necessária a correta previsão das quantidades de espécies intermediárias - tem se servido, para atingir tal fim, de abordagem 
invariavelmente cinético-química.

\subsection{Modelagem pseudo-termodinâmica e ques- tões de equilíbrio local}

Informações termoquímicas obtidas pelo que se chamará de análise pseudotermodinâmica têm sua relevância ou aplicabilidade limitada por restrições de origem físico-químicas quanto à validade da hipótese subjacente, de equilíbrio global, ou pela não consistência dos modelos em validação eventual de hipótese de equilíbrio local (conforme fundamentação teórica explicitada adiante).

Chamar-se-á essa abordagem de pseudo-termodinâmica porque nela, considera-se a chama como um todo em equilíbrio (homogêneo), o que não ocorre na prática, dada as diferenças espaciais de fração molar das espécies e das temperaturas presentes. Essa simplificação que é inerente à morfologia desse modelo, impede a priori, que as condições necessárias para se atingir o equilíbrio (que ele pressupõe) possam ser satisfeitas. Este estudo pretende questionar se essa simplificação pode estar na origem de a termodinâmica assim formulada não conseguir prever o perfil de chama. Caso o modelo não satisfaça essa necessidade, ele pode, por hipótese, violar a possibilidade de se encontrar uma condição local de equilíbrio, mesmo que ela esteja de fato presente.

Para se estudar a chama com o auxílio da termodinâmica, faz-se a hipótese de que equilíbrio local (LTE) seja aplicáve ${ }^{4}$.

\footnotetext{
${ }^{4}$ o equilíbrio termodinâmico é válido apenas para os pontos na vizinhança do ponto em equilíbrio. Embora tais sistemas não estejam estritamente em equilíbrio, desde que o tempo de relaxação microscópico seja desprezível em relação ao tempo macroscópico característico
} 
Indício de que o equilíbrio possa prevalecer em chamas de pré-mistura estão no fato de a ordem de grandeza do tempo de reações elementares serem da ordem de femtosegundos $\left(10^{-15} \mathrm{~s}\right)$ enquanto que as reações de uma chama se completam em milisegundos $\left(10^{-3} s\right)$.

\subsection{A abordagem exergética e as chamas}

Depois dos anos 50, houve tentativas de se utilizar a abordagem metodológica da análise exergética também no contexto de chamas de pré-mistura. Devese lembrar que a abordagem exergética utiliza-se de uma análise combinada de primeira e de segunda lei, permitindo, a princípio identificar, em cada transformação, potenciais fontes internas de irreversibilidade e que aumentam a imperfeição termodinâmica ${ }^{5}$ - no quesito rendimento exergético - dos processos avaliados SZARGUT (1980). Nesse tipo de análise procura-se, acima de tudo permitir comparar quantitativamente e qualitativamente as diferentes interações de energia, atribuindo-se valores a elas que permitam comparação direta, bem como quantificação numérica.

BAEHR (1979), BISIO; RUBATTO (2000) afirmam que a introdução do conceito de exergia foi ocasionado por dois fatos empíricos:

i. Nem toda forma de energia pode ser convertida em outra forma de energia, pode-se aplicar a termodinâmica para analisar as propriedades locais, subdividindo o sistema em subsistemas menores. Embora as fronteiras de cada um desses subsistemas seja imaginária e até certo ponto arbitrária para fins de análise, não representando nenhuma fronteira física, a lógica da termodinâmica ainda pode ser aplicada a esses sistemas. Em sistemas em LTE, para as escalas de tempo de interesse, todos os graus de liberdade estão em equilíbrio.

${ }^{5}$ rendimento exergético inferior à unidade. 
pois a segunda lei limita a possibilidade de conversão de energia;

ii. Toda conversão de energia é limitada e influenciada pelo meio em que o processo de conversão de energia ocorre.

BISIO; RUBATTO (2000) dizem que a exergia nos fornece uma visão quantitativa e ilustrativa da convertibilidade de diferentes formas de energia, sem ter o objetivo de uma nova formulação da segunda lei, mas se contradizem ao definirem o que chamam de "exergia útil", em transformações de combustão. Sob o pretexto de que o "efeito útil" seja a transferência de calor, sugerem que é necessário levar em conta a existência de processos inerentemente irreversíveis. Alegam, para justificar esse parâmetro, que, ao contrário da definição de exergia, o trabalho responsável pela expansão reversível de vários componentes (principlamente o $\mathrm{CO}_{2}$ ) não pode ser obtido na prática. Acredita-se ser essa terminologia de pouca utilidade, violando mesmo o conceito de exergia, que, sob essa visão, perde sua característica principal que é a de poder comparar processos distintos sob uma mesma base teórica.

O método exergético, afirmam BISIO; RUBATTO (2000), tampouco nega a validade da equação da entropia gerada, amplamente empregada. Com relação a esta última, no entanto, o método de análise exergética reconhece, dizem, a influência do meio nas conversões de energia possíveis e permite comparar processos distintos de forma quantitativa, além de definir eficiências baseadas na segunda lei (GALLO; MILANEZ, 1990).

A análise exergética nos informa o máximo trabalho passível de ser obtido de uma dada forma de energia, utilizando os parâmetros do ambiente $\left(p_{0}, T_{0}, \mu_{0 i}\right)$ como aqueles do estado de referência KOTAS (1985), i.e. que ocorre quando o sistema, através de um processo reversível, entra em equilíbrio irrestrito - térmico, 
mecânico e químico - com o meio com o qual está interagindo. Há outra definição que diz que a exergia é o trabalho mínimo necessário para se construir um sistema a partir do ambiente de referência LOZANO; VALERO (1993). Deve-se explicitar, dizem ainda BISIO; RUBATTO (2000), que a exergia é função do sistema e do meio - deste, através do estado de referência - enquanto que a entropia é função exclusiva do sistema. Não faz sentido, nem se pode, fazer uma análise desse tipo sem se identificar contra o quê o sistema pode, em princípio, realizar trabalho, i.e. qual o meio que o circunda.

A análise exergética introduz o termo trabalho perdido, que é a parcela da exergia que é destruída e que não pode ser convertida em trabalho. É nula em processos reversíveis.

Um dos resultados interessantes da análise exergética, segundo RATKJE; ARONS (1995), é a existência, no projeto de equipamentos de processos, de pontos ótimos termodinâmicos. No caso de processos que envolvem reações químicas o encontrar desse ponto ótimo reflete a "disputa" entre o se manter, na troca de calor, as diferenças de temperatura em valores mínimos - reduzindo-se as perdas - e no se maximizar essas mesmas temperaturas para se incrementar a "força motriz" das reações - tornando o processo mais veloz (e reduzindo-se, pois, a dimensão dos equipamentos envolvidos).

É possível - e será objeto desta investigação - que a Natureza venha a se utilizar desse mesmo princípio ao nos proporcionar uma chama de pré-mistura. Para que essa investigação seja possível, a importância relativa desses processos devem poder ser comparáveis, trazendo novamente à tona a imensa utilidade da análise exergética. 


\subsubsection{Análise exergética: o estado de referência}

Para que a análise exergética possa ser feita, precisa-se contextualizar o sistema em relação ao meio do qual participa/com o qual interage. O estado em que se encontra o meio, segundo BISIO; RUBATTO (2000) tem importância significativa no cálculo de exergia de sistemas quimicamente reativos. Segundo AHRENDTS (1979):

"[...] é importante mencionar que a teoria termodinâmica não nos indica que tipo de sistema deveria fazer o papel de reservatório (responsável por determinar o estado de referência). Na maioria das aplicações, o reservatório é escolhido por intuição de engenharia e por argumentos de utilidade, sem se reportar à teoria termodinâmica. Há uma crescente aplicação do conceito de disponibilidade na análise de processos químicos, mas as dificuldades em se escolher sistemas de referência adequados são suplantadas, a penas, por hipóteses de engenharia."

Ainda segundo BISIO; RUBATTO (2000), a definição de um sistema de referência é problemático, pois o ambiente, via de regra, não está em equilíbrio.

Segundo GALLO; MILANEZ (1990), há uma diversidade de metodologias e/ou abordagens para se eleger um estado de referência quando da análise exergética. DENBIGH (1956), que sugere o uso do estado de referência restritc ${ }^{6}$ somente quando a exergia termomecânica puder ser avaliada sem sofrer alterações (SZARGUT, 1980). SZARGUT (1980) adotaram um "meio padrão", com temperatura, pressão e composição químicas fixas. Todos, sem exceção, envolvem premissas, que por praticidade, são até certo ponto arbitrárias. O meio, ainda segundo GALLO; MILANEZ (1990), não está, via de regra, em equilíbrio químico e como a quantidade de exergia depende do estado do meio, esta referência sofreria

\footnotetext{
${ }^{6}$ estado em que há equilíbrio térmico e mecânico com o meio.
} 
mudanças sempre que o meio viesse a sofrer alteração.

Se um sistema em não-equilíbrio for escolhido, partes do meio terão exergia uma em relação à outra. Por outro lado, um meio que esteja em equilíbrio exclui a presença de fontes de energia e impede a ocorrência dos processos cuja efetividade estejamos examinando. Não há, assim, estado de referência que satisfaça os dois quesitos a contento.

Ainda, para AHRENDTS (1979), a composição de uma atmosfera em equilíbrio difere significativamente de sua composição real. Cálculos demostraram que a atmosfera da Terra, em equilíbrio, conteria apenas uma quantidade diminuta de oxigênio livre, insuficiente à manutenção da vida, enquanto que uma parte significativa do oxigênio disponível estaria ligado em forma de nitratos. Por esse e outros motivos, como sensibilidade a diferenças de temperatura e de fração molar, segundo SZARGUT (1962), o ambiente natural não parece ser um bom candidato a sistema de referência.

Por esses motivos, vários modelos descrevendo o estado de referência são utilizados:

i. Ambientes de Referência Parciais:

- um ambiente parcial;

- um meio em relação a um processo;

ii. Ambientes de Referência Gerais:

- um ambiente artificial;

- um ambiente em equilíbrio; 
- um ambiente consistindo de substâncias referência de valor exergético nulo.

Ambiente parcial : são definidos de acordo com as especificidades do processo analisado. Baseia-se no fato de que algumas das evoluções do estado de um sistema não poderem ser atingidas por limitações de processo. Por esse motivo, apenas as evoluções que o sistema pode atingir são analisadas. $\mathrm{O}$ ambiente parcial não é um de "dead state".

Meio em relação a um processo : um modelo em que apenas componentes que participam do processo sendo examinado e que estejam em uma composição de equilíbrio à pressão e temperatura do ambiente fora proposto BOSNJAKOVIC (1963). Essa referência é função do processo sendo analisado e não é geral. O modelo adotado no trabalho exposto nesta Tese é uma variante desse modelo em que a temperatura de referência é calculada e não é necessariamente igual à temperatura do ambiente.

Ambiente artificial : de não equilíbrio. Proposto por SZARGUT (1962), contém uma substância referência para cada elemento. Segundo AHRENDTS (1979), escolhidas por um critério econômico, abrem espaço para escolhas arbitrárias. Os potenciais químicos das substâncias escolhidas são fixadas pelo seu estado de ambiente natural e todas as outras substâncias têm seus potenciais químicos derivados de uma condição de equilíbrio entre elas e as substâncias referência a partir de suas reações de formação com as substâncias de referência, atendendo, portanto, a princípio, a condição de equilíbrio necessária. $\mathrm{AH}-$ RENDTS (1979) afirma que um sistema físico em equilíbrio correspondendo aos 
potenciais químicos propostos para as substâncias referência não existe. Como consequência, disponibilidades negativas de substâncias em equilíbrio térmico e mecânico com o sistema de referência podem ocorrer.

Ambiente em equilíbrio : desenvolvido por AHRENDTS (1979), a partir do conceito de ambiente artificial. Leva em conta que se a quantidade de elementos diferentes em um sistema de referência for conhecido e sua temperatura fixada, a quantidade de cada composto e o valor de cada potencial químico é univocamente determinada ao se fazer prevalecer a condição de equilíbrio químico. Situações de equilíbrio forçado seriam identificáveis nesse sistema e dessa forma se conseguiria determinar se dado estado de referência seria apropriado. AHRENDTS (1979) escolheu 17 elementos que se permitiu reagirem em um modelo mixto sólido-líquido-gasoso, representando a atmosfera, os oceanos e a crosta terrestre. Quando esse sistema é modelado sem a possibilidade de formação de compostos nítricos, por exemplo, obtém-se condições muito semelhantes ao de um ambiente natural a $p^{R}=1.019 \mathrm{~atm}$, mas se obtém disponibilidades negativas em alguns compostos, por não estarem a água e o ar em equilíbrio com relação à formação de ácido nítrico diluído. Ao se retirar a inibição de compostos nítricos, cuja formação então passa a ser permitida, o sistema resultante se apresenta significativamente diferente do ambiente natural.

Ambiente consistindo de substâncias de valor exergético nulo : a propriedade de um sistema de referência composto de substâncias de valor exergético nulo, mas não em equilíbrio termodinâmico é uma fraqueza dessa abordagem. Isso porque a conversão espontânea de substâncias de referência (de valor exergético nulo) produz necessariamente compostos com exergia negativa, exergias essas que não são consideradas na definição de exergia. Assim, processos que 
resultam em produtos com exergias negativas (produzidos a partir de substâncias de referência) devem ser excluídos dessa espécie de análise.

BISIO; RUBATTO (2000) analisam à ótica imposta pela análise exergética clássica: o sistema deve estar num estado de equilíbrio interno irrestrito, e o meio deve estar num estado de equilíbrio interno irrestrito, e que não sofram variações com o tempo. Devendo ambos os estados ser de equilíbrio irrestrito, deduz-se, para que haja esta equivalência, que o máximo trabalho possível (reversível) e o de afastamento do estado do sistema do estado do meio não são equivalentes.

Para se ter uma formulação exergética, a possibilidade de reversibilidade, ao menos como um limite, é necessária, o que não pode ser feito para estados de não equilíbrio (nem como um limite).

Através de conceitos como trabalho perdido e estado de referência restrito (pressão e temperatura do ambiente sem movimento, de onde se obtém o potencial termomecânico) e irrestrito (que inclui também o potencial químico, por esse estado de referência incorporar além da pressão e temperatura do ambiente sem movimento macroscópico, também a sua composição química) a análise exergética permite, em teoria, efetuar análises comparativas entre transformações de natureza distinta. Na prática, há a necessidade de se trabalhar com sistemas termodinâmicos, i.e. de se identificar em que circunstâncias ou com que restrições o sistema se comporta dessa forma.

GALLO; MILANEZ (1990) dizem que para otimização de uma dada transformação, a identificação de irreversibilidades internas - e seu cálculo - podem ser feitas através de uma avaliação de entropia gerada ou por uma análise exergética, sem necessidade de se dar muita importância ao estado de referência. Mas: 
"[...] para se poder comparar diferentes transformações, por exemplo - e para se fazer estudos exergéticos que envolvam quantificação e controle de poluentes, a escolha do estado de referência se torna primordial, mas por ... (a Terra) não ser um sistema isolado, não é possível de se definir um ambiente de referência a princípio correto teoricamente."

Ainda, segundo BISIO; RUBATTO (2000) a escolha de espécies de referência para o cálculo da exergia química não influencia os valores das irreversibilidades internas, mas influencia significativamente o valor das irreversibilidades externas, e portanto influencia também o valor da eficiência exergética. Continuam, dizendo que as espécies de referência deveriam representar os produtos de uma interação entre os componentes do ambiente e os produtos finais resultantes de processos. Os produtos mais prováveis dessa interação deveriam ser escolhidos como espécies de referência.

Indicativo que a busca de um estado de referência mais consistente do ponto de vista teórico (ou fundamental) se faça necessário e que um estado de referência assim definido seja função das especificidades do sistema em questão, não sendo necessariamente o estado encontrado dessa forma, coincidente com nenhum dos utilizados corriqueiramente em análise exergética. Sabe-se (BISIO; RUBATTO, 2000) que a exergia de um fluxo depende da escolha do sistema de referência, que nada mais é do que o nível zero em relação ao qual o trabalho reversível possa ser calculado. Acredita-se ser o estado de referência específico e exclusivo de cada chama i.e. para cada conjunto de reagentes, e que este estado, ao contrário do que dizem BISIO; RUBATTO (2000), não se constitua de espécies mais prováveis produtos da interação reativa, mas que sejam efetivamente a representação teórica - do fenômeno em equilíbrio viz. a chama reversível, que se poderia chamar de meio. Discorda-se de AHRENDTS (1979), também, quando este 
diz que por a disponibilidade depender de um estoque de espécies químicas que é dado circunstancialmente, e por não ser este um critério termodinâmico (o planeta não está em equilíbrio), um sistema de referência em equilíbrio exclusivo não pode ser selecionado por raciocínio exclusivamente termodinâmico. A chama reversível, ao dispor de um estoque de espécies químicas bem determinado e em equilíbrio local- e função dos reagentes que a compõem - é um contra-exemplo dessa forma de se pensar. É um exemplo de meio gerado através de raciocínio puramente termodinâmico.

Embora a escolha do estado de referência seja óbvia de acordo com alguns autores, é, ao contrário, problemática pois todo meio que se utiliza corriqueiramente está em um estado de não equilíbrio e uma escolha individual de estado de referência, caso a caso, se faz necessária. Segundo BISIO; RUBATTO (2000), a escolha de espécies de referência para exergia química não influenciam o valor das irreversibilidades internas, mas influenciam consideravelmente os valores das perdas externas e portanto, o valor da eficiência exergética. Portanto, a escolha de espécias de referência apropriadas são mandatórias. Acredita-se que a escoIha de um estado de referência interno (ou intrínseco) seja fundamental para que se possa identificar as irreversibilidades internas. Por transmitir a máxima exergia possível de ser atingida internamente, esse estado de referência constitui um parâmetro que permite identificar o teto das perdas internas. Ao encontro desse fato, neste estudo a análise de estado de referência interno será condição necessária para que se justifique uma abordagem termodinâmica de chamas de pré-mistura: será através deles que se procurará inserir a chama de pré-mistura em um contexto termodinâmico.

DENBIGH (1956) analisa à luz da segunda lei, a magnitude de eficiência de uma transformação química, utilizando-se do conceito de disponibilidade de KE- 
ENAN (1941). Conclui que a transformação mais eficiente é aquela que requer o trabalho mínimo ou menor quantidade de transferência de calor a uma dada temperatura. Já se nota nesses primórdios, seguindo GIBBS (1948) a denominação de meio (medium) para as condições de referência, usualmente compreendidas como sendo as condições de ambiente (environment), mas não completamente esclarecidos em publicações. É o que KOTAS (1985) entende como sendo o ponto morto (dead state) ${ }^{7}$

DENBIGH (1956) afirma, ainda, que reações químicas deveriam ocorrer sob "condições resistidas" (resisted conditions) para que elas pudessem desenvolver trabalho útil, sem discriminar o que seriam exatamente tais condições. Chama-se essa condição, neste modelo, de ponto de ignição local. Na composição deste modelo de chama há uma infinidade de pontos nesta situação. A chama sob esta ótica, teria em sua composição uma infinita sequência de pontos de ignição. Eles são responsáveis pelas alterações - em estado estacionário, sempre muito rápidas - de temperatura e da composição em chama.

\subsubsection{Geração de entropia em chamas}

Muitas das tentativas de se avaliar exergeticamente o processo de combustão se atêm à análise da influência na exergética de variáveis externas ao processo de combustão em si, i.e. de chama. Variáveis consideradas externas por serem impostas externamente ao sistema, como a temperatura e pressão dos reagentes bem como a razão de equivalência da mistura em contraposição a variáveis relacionadas à estrutura de chama, de natureza interna, como as reações quími-

\footnotetext{
${ }^{7}$ é o estado em que o sistema se encontra em equilíbrio térmico, mecânico e químico com o meio.
} 
cas, a troca interna de calor, a difusão mássica e a condução de calor. Naquele tipo de análise, de caixa preta, não temos acesso ao que ocorre internamente à chama.

Internamente à chama, ter-se-ia, via de regra, ocorrendo concomitantemente ou não os seguintes processos irreversíveis: difusão térmica, condução térmica, difusão mássica, difusão química, troca de calor entre os subsistemas, escoamento viscoso, escoamento viscoso difusivo e reações químicas, segundo TENG; KINOSHITA; MASUTANI (1996); NISHIDA; TAKAGI; KINOSHITA (2002); LIOR; SARMIENTO-DARKIN; AL-SHARQAWI (2006). Sempre que esses processos estão presentes, o trabalho potencialmente extraível entre um estado e o estado de referência é menor que o trabalho reversível.

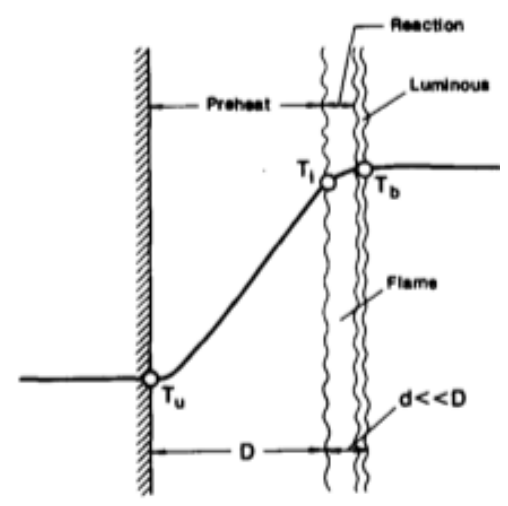

Figura 3.1: Distância mínima de propagação de chama, extraído de (ARPACl; SELAMET, 1988)

Dentre as primeiras tentativas de se avaliar a produção de entropia em chamas, vemos ARPACl; SELAMET (1988) relacionarem a mínima distância de propagação de chama, $D$, à sua geração de entropia, figura 3.1. Associaram a entropia gerada numa chama de pré-mistura laminar unidimensional a um número adimensiona $8^{8}$ e estudaram sua variação em função de $D$.

\footnotetext{
${ }^{8} \Pi=s^{\prime \prime \prime} \times \frac{l^{2}}{k}$; onde $s^{\prime \prime \prime}$ é a entropia gerada localmente, $l$ é o comprimento característico de
} 
Esse número adimensional - deduzido da parte térmica da segunda lei da termodinâmica $9^{9}$ em conjunto com a consideração que a troca de calor se dá por conduçãd ${ }^{10}$ ao longo da distância mínima de propagação - foi identificado como sendo inversamente proporcional ao quadrado do número de Peclet $_{D}{ }^{11}$. função da distância mínima de propagação de chama ${ }^{12}$, esta relacionada a um ponto de máximo na geração de entropia.

Concluem que a geração de entropia entre a chama e o queimador se mantém, de início, aparentemente constante, crescendo então de forma rápida e segundo eles, sem aparente justificativa, mas que pode-se sugerir com relativa segurança se dever às particularidades de haver uma aproximação do que se chama de ponto de ignição, em que um aumento na velocidade de transformação tende a favorecer as perdas, podendo ainda intensificar a geração de entropia.

Em uma alusão ao artigo de DENBIGH (1956), RATKJE; ARONS (1995) apresentam o que clamam como sendo uma nova forma de se calcular o trabalho perdido em uma mistura reativa-difusiva, identificando um meio-termo entre o aumentar da força-motriz - para acelerar a velocidade de reações - e o de se reduzir o custo de equipamentos, com a consequência no aumento de trabalho perdido. Fazem isso utilizando uma abordagem de termodinâmica de não equilíchama ( $l=\frac{\alpha}{S_{u}}$ onde $S_{u}$ é a velocidade de chama adiabática laminar); $\Pi$ relaciona a entropia gerada localmente ao comprimento característico de chama e à $k$, sua condutividade térmica; ${ }^{9} s^{\prime \prime \prime} \sim \frac{1}{T} \times \frac{q^{K}}{T} \times \frac{T_{b}-T_{u}}{D}$; onde $q^{K}$ é a transferência de calor por condução ao longo de chama, $T_{b}$ a temperatura dos gases queimados e $T_{u}$ a temperatura dos reagentes e $D$ a distância mínima de propagação de chama (distância entre os reagentes puros e o "ponto de ignição") - ou quenching distance;

${ }^{10} q^{K} \sim k \times \frac{T_{b}-T_{u}}{D}$

${ }^{11} \mathrm{Pe}=\frac{L \times U}{\alpha}$ onde $\mathrm{L}$ é o comprimento característico de advecção, $\mathrm{U}$ é a velocidade de advecção e $\alpha$ o coeficiente de difusividade térmica da chama.

${ }^{12}$ distância entre os reagentes e o local onde se dá a ignição (quenching distance). 
brio, limitando o estudo deles ao acoplamento entre as forças térmicas e químicas de sistema, tentando reduzir as perdas de disponibilidade.

RATKJE; ARONS (1995) afirmam que o seu trabalho é uma extensão do trabalho de DENBIGH (1956) e que ainda falta uma formulação matemática do que ele chamou de "condições resistidas", enunciada acima. Segundo eles, tratam da conversão de energia química e de mistura em trabalho e da questão de como o trabalho perdido possa ser minimizado.

RATKJE; ARONS (1995) comparam as formas de calcular a entropia gerada central, segundo eles, especialmente no contexto de processos adiabáticos - através de uma análise exergética (análise de caixa preta) e através da termodinâmica de processos irreversíveis (análise fenomenológica). Prosseguem, dizendo que a análise exergética trata de variáveis macroscópicas, finitas, sem incluir a variável tempo ou de qualquer detalhe de como o sistema se processa entre os estados inicial e final, informação essa, disponível somente no âmbito de termodinâmica clássica irreversível e, de fundamental importância, segundo eles, para determinar a magnitude do trabalho perdido.

A análise de perda de disponibilidade devido a reações químicas através da ferramenta de termodinâmica clássica irreversível segundo RATKJE; ARONS (1995), implica existência de equilíbrio local, equilíbrio este, dizem eles, ainda, não validado em nível molecular para reações químicas.

RATKJE; ARONS (1995) completam então, dizendo que as teorias de análise exergética e de termodinâmica de processos irreversíveis podem ambas serem usadas para quantificar a destruição de exergia de um processo e que enquanto a análise exergética apresenta uma forma de se comparar processos utilizando-se exclusivamente de informação termodinâmica, a referência ao ambiente inclusa 
em análise exergética não está contida, a priori, na análise de termodinâmica de transformações irreversíveis, mas que a teoria da termodinâmica de processos irreversíveis tem outra vantagem: critérios que minimizam a perda de disponibilidade em sistema podem ser deduzidos de relações entre fluxos e forças ${ }^{13}$.

Ainda, dizem RATKJE; ARONS (1995), a entropia gerada tem significados diferentes em cada uma dessas teorias, sendo um valor de caixa preta na análise exergética e um valor local, na termodinâmica de processos irreversíveis.

Segundo SOM; DATTA (2008), grosso modo, $\frac{1}{3}$ da exergia é destruída no processo de combustão. Cita LIOR; SARMIENTO-DARKIN; AL-SHARQAWI (2006) quando enumera a necessidade de análise de transformações de combustão baseada em segunda lei para:

- Identificação de fenômenos e processos que têm destruição de exergia ou irreversibilidades significativas;

- Compreender o porquê da destruição de exergia;

\footnotetext{
${ }^{13}$ na termodinâmica de processos irreversíveis, ou termodinâmica de não equilíbrio a taxa de geração de entropia é determinada pelo produto de fluxos $\left(J_{i}\right)$ por forças $\left(\nabla X_{j}\right)$, sendo os fluxos proporcionais às forças, estas, motrizes dos fluxos através de leis empíricas, como por exemplo a Lei de Fourier que diz que a densidade do fluxo de calor $\left(\frac{d q}{d t}\right)$ se relaciona com o gradiente de temperatura $(\nabla T)$ através de $\frac{d q}{d t}=k \times \nabla T$, onde $k$ é a condutividade térmica do meio em questão. Essas relações, via de regra lineares, são parametrizadas por uma matriz $\left(L_{i j}\right)$ que relaciona os fluxos, ou densidades de fluxo, às forças:

$$
J_{i}=\sum_{j} L_{i j} \times \nabla X_{j}
$$

As relações de Onsager (ONSAGER (1931)) nos dizem que a matriz $L_{i j}$ é simétrica. A relação linear 3.1 vale para condições estacionárias não distantes do equilíbrio. Sabe-se que nessas condições as densidades de fluxo são duais das forças.
} 
- Avaliar qual a sensibilidade dessas irreversibilidades aos parâmetros de processo; e finalmente,

- Sugerir formas de melhoria em processo.

Ainda segundo SOM; DATTA (2008), as seguintes seriam as principais fontes de redução de irreversibilidade em transformações de combustão:

- Redução de trocas térmicas internas à chama;

- Manutenção de altas temperaturas em chama;

- Redução de condução de calor devido ao processo de mistura, i.e. para que haja uma redução de irreversibilidade, o processo de mistura deve ocorrer com gradientes menores de temperatura (chamas de não pré-mistura);

- Estudos sobre a influência de turbulência e vorticidade em geração de entropia para diferentes tipos de chama bem como a influência de pressão na eficiência exergética em chamas a alta pressão;

- O projeto mais adequado de sistemas de geração de trabalho (máquinas térmicas).

SOM; DATTA (2008) citam que altas temperaturas de chama podem ser conseguidas via enriquecimento (do processo de combustão) com oxigênio. Embora tal enriquecimento efetivamente aumente a temperatura média de chama, em teoria promovendo aumentos de eficiência exergética ${ }^{14}$, esse incremento pode ocorrer também com aumento das trocas térmicas entre os subsistemas da chama com detrimento de aumento em eficiência exergética. Parece existir um ótimo nesse sentido pois aumenta-se, com esse procedimento, a temperatura média de chama

\footnotetext{
${ }^{14}$ razão entre a exergia que sai e a exergia que entra no sistema em análise.
} 
com contrapartida de aumentos internos de gradientes de temperatura.

LIOR; SARMIENTO-DARKIN; AL-SHARQAWI (2006) afirmam que enquanto a maioria de estudos feitos até então é conduzido de tal forma que se identifica variações de exergia de componentes de sistema, estes não fornecem informações detalhadas de processos/fenômenos específicos que influenciam em variações de exergia, e que muitas vezes são função do tempo e do espaço. Chamam esta categoria de análise a ser feita de "intrínseca" - transferência de calor, transferência de massa, processos fluido mecânicos, reações químicas ou nucleares, etc. - a serem feitas em uma segunda fase de desenvolvimento, e de grande valor em quesito de inovação de projeto de tais sistemas. DUNBAR; LIOR (1991) se auto-proclamam os primeiros a avaliarem as causas primárias de irreversibilidade em chamas (no caso, de chamas de não pré-mistura) que identificaram como sendo:

- a oxidação do combustível e a difusão de espécies, combinados (rendimento exergético de $94 \%$ a $97 \%$ );

○ "trocas térmicas entre os subsistemas" (troca de calor) - responsável por $\frac{3}{4}$ da destruição de exergia;

○ o processo de mistura dos produtos.

Citam ainda GAGGIOLI (1961) quando afirmam que de todos os processos/transformações ocorrendo em uma típica planta de geração de energia, a transformação de combustão é aquela que mais contribui, de forma exclusiva, para destruição de exergia, ressaltando o interesse em se determinar as magnitudes de suas causas. Cita trabalhos anteriores, por exemplo ARPACl; SELAMET (1988) para apontar que praticamente nenhuma conclusão de estudos anteriores resultou em melhorias de processo. 
Após constatarem que a destruição de exergia em combustor de turbina girava entre $20 \%$ e $30 \%$ e que era a maior perda dentre a de todos os componentes, NISHIDA; TAKAGI; KINOSHITA (2002) analisaram em seu estudo a entropia gerada localmente em uma chama de pré-mistura, devido aos processos de dissipação viscosa, condução de calor, difusão mássica e devido a reações químicas. Levou-se em conta mecanismos cinético-químicos detalhados e difusão multicomponente, seguindo a formulação de HIRSCHFELDER; CURTISS; BIRD (1955) da Segunda Lei da Termodinâmica ${ }^{15}$

Em NISHIDA; TAKAGI; KINOSHITA (2002), o processo de análise de combustão envolveu resolver as equações de conservação de massa, de conservação de quantidade de movimento, de conservação de energia e de "conservação" de espécies químicas, levando em conta a cinética detalhada e difusão multicomponente para 8 espécies químicas. NISHIDA; TAKAGI; KINOSHITA (2002) resolveram essas equações utilizando o método de diferenças finitas. Na análise da segiunda lei da termodinâmica feita por NISHIDA; TAKAGI; KINOSHITA (2002) as espécies químicas escolhidas foram:

$$
{ }^{15} \rho \frac{D S}{D t}=\frac{1}{T} \overbrace{\left[-(\tau: \nabla v)-\left(q_{c} \cdot \nabla \ln T\right)-\left(\sum_{i} j_{i} \cdot \nabla \mu_{i^{\prime}}\right)-\left(\sum_{i} \mu_{i} \cdot r_{i}\right)\right]}^{\mathrm{I}}-\overbrace{\left[\nabla \cdot\left(\frac{q_{c}}{T}+\sum_{i} j_{i} \cdot S_{i}\right)\right]}^{\mathrm{II}} ;
$$
onde:

I: parcela de fonte de entropia, consistindo de taxa de geração de entropia devido a viscosidade, condução de calor, difusão de massa e reação química, respectivamente, e;

II: parcela de difusão, compreendendo os termos correspondentes à condução de calor e à difusão de massa, respectivamente. Ainda:

$\rho$ é a massa específica, $S$ é a entropia, $T$ é a temperatura, $\tau$ é o tensor de tensão viscosa, $v$ é o vetor velocidade, $j_{i}$ é o vetor fluxo de massa da espécie $i, r_{i}$ é a constante de reação da espécie $i$ e $S_{i}$ a entropia da espécie $i . q_{c}=q-\sum_{i}\left(H_{i} j_{i}\right)$ e $H_{i}=T S_{i}+\mu_{i}$ e $\nabla \mu_{i^{\prime}}=\nabla \mu_{i}+S_{i} \nabla T$, onde $q$ refere-se ao vetor de fluxo de calor e $H_{i}$ à entalpia da espécie $i$. 


$$
\mathrm{H}_{2}, \mathrm{O}_{2}, \mathrm{~N}_{2}, \mathrm{H}_{2} \mathrm{O}, \mathrm{O}, \mathrm{H}, \mathrm{OH}, \mathrm{HO}_{2}
$$

e 16 reações elementares em combustão de hidrogênio gasoso com ar, para escoamento laminar, em regime permanente e unidimensional, obtendo-se as frações molares, velocidades e temperatura de análise numérica de processo de análise de combustão - utilizou-se o programa CHEMKIN (KEE, 1985) que também forneceu à análise as propriedades termodinâmicas e de transporte (KEE et al., 1986; KEE; RUPLEY; MILLER, 1987) ao processo de análise de combustão.

Identificaram-se as parcelas que caberiam à geração de entropia por conta de dissipação viscosa, condução de calor, difusão mássica e devido a reações químicas, enumerados acima.

Concluiu-se que a taxa total de geração total de entropia é alta na região principal de reação e que a entropia gerada devido a reações químicas corresponde a 72,6\% do total de entropia gerada em chama. Como se discutiu em ARPACI; SELAMET (1988) acima, esse fato se justifica fisicamente.

Atribuiu-se, ainda, ao processo de condução de calor $21,6 \%$ desse total e que a contribuição de difusão mássica é muito menor de que a desses dois e que as perdas viscosas seriam desprezíveis. Por ter relevância prioritária no processo de combustão, é aparente que a conclusão de NISHIDA; TAKAGI; KINOSHITA (2002) de que a entropia gerada pelos processos reativos tenha significativa importância seja consistente com a realidade física desse fenômeno.

Em pesquisas envolvendo geração de entropia em chamas que se utilizam da análise exergética, há uma lacuna termodinâmica pois as espécies são calculadas em se utilizando a cinética química, lacuna esta que pretendemos tentar ajudar a preencher, ao levantar a hipótese de equilíbrio local, testando um modelo termodinâmico das reações de chama, à luz da termodinâmica clássica. 
O teste dessa hipótese permitirá, ao tentar alterar o escopo de modelagem, comparar as potenciais diferenças e vantagens de uma análise clássica que conte com regiões em equilíbrio local contidas, em estado estacionário, em descontinuidades, em contraposição a uma análise de não equilíbrio, seguindo a formulação, principalmente de ONSAGER (1931), mas também de GLANSDORFF; PRIGOGINE (1971), ZIEGLER (1983), PALTRIDGE (1978) e PALTRIDGE (1979), dentre outros, em que os sistemas não são considerados como tendo descontinuidades puntuais, mas estão em condições de não equilíbrio.

\subsubsection{Princípios de extremos de geração de entropia}

Houve um relativo sucesso em ótica (princípio de Fermat) e em mecânica (princípio da mínima ação, de ação estacionária ou princípio de Hamilton), que permitiu que leis da mecânica clássica pudessem ser derivadas de forma consistente e trivial, mesmo para sistemas complexos. A trajetória de um sistema mecânico é tal que sua açãd ${ }^{16}$ atingisse um extremo, normalmente um mínimo. Os princípios de mínima ação e o princípio de conservação de energia são simplesmente duas formas de se expressar as mesmas leis da Física, baseadas nas Leis de Newton.

À luz de uma teoria chamada de termodinâmica de processos irreversíveis, PRIGOGINE (1947) elaborou o que chamou de Princípio de Minimização de Entropia Gerada (EGM). Propõe que processos irreversíveis que entrem em regime estacionário, o façam seguindo esse princípio. Fornece um critério para determinar o regime permanente de um sistema em que ocorre um processo irreversível.

Tentativas de se encontrar uma função universal cujo extremo pudesse deter-

${ }^{16} \int(T-U) \mathrm{d} t$, onde $T$ é a energia cinética e $U$ é a energia potencial generalizadas do sistema e $t$ a variável tempo de um dado sistema. 
minar o funcionamento de um sistema sempre existiram. O problema de se aplicar o princípio de mínima dissipação de energia para se obter a relação entre interações mútuas em um sistema foi finalmente resolvido por ONSAGER (1931), que ao invés aplicou o princípio da reversibilidade microscópica e provou as relações de Onsager. O depois chamado Princípio de Máxima Produção de Entropia (MEPP), foi por muito tempo negligenciado e é bem menos conhecido (MARTYUSHEV; SELEZNEV, 2006), mesmo sendo anterior àquele. Recentemente tem sido enfatizado que ele poderia ser uma ferramenta útil para encontrar a trajetória de processos envolvendo transformações químicas (HILLERT; ÅGREN, 2006).

Esse aparente antípoda do EGM tem sido ofuscado pelo princípio gêmeo. Assim, além de uma direção de evolução, dada pela segunda lei, propoẽ-se uma informação sobre seu movimento (MARTYUSHEV; SELEZNEV, 2006).

A relação entre os dois princípios não é trivial e os princípios variacionais são significativamente diferentes (as restrições são distintas e os parâmetros variáveis também). Esses dois princípios não devem, no entanto ser colocados em oposição pois são, a princípio responsáveis por descrever estágios de evolução distintos de um sistema em não-equilíbrio (MARTYUSHEV; SELEZNEV, 2006). O princípio de mínima produção de entropia PRIGOGINE (1947) é válido para situações onde os fluxos são mantidos constantes. O princípio de máxima produção de entropia ZIMAN (1956) é válido para situações onde as forças são mantidas constantes REIS (2014), no âmbito da termodinâmica dos processos irreversíveis. Nenhum dos dois prevê situações em que a temperatura de referência varie.

O critério de PRIGOGINE (1947) pode ser formulado de forma bastante simples: o regime permanente é o estado em que a taxa de entropia gerada tem um valor mínimo consistente com as restrições externas que impedem o sistema de atingir 
o equilíbrio. Quando não há condicionantes, o sistema evolui para o estado em que a taxa de geração de entropia é nula, i.e. o estado de equilíbrio. Foi deduzido para um sistema em condições de não-equilíbrio, mas próximas a condições de equilíbrio (no domínio dito linear). Quando condicionantes como por exemplo uma diferença de temperatura mantida entre partes de um sistema impedirem o sistema de atingir o equilíbrio, o sistema adota a melhor alternativa seguinte: vai a um estado em que as variáveis termodinâmicas não se alteram com o tempo e em que a menor quantidade possível de entropia é gerada por unidade de tempo (KLEIN; MEIJER, 1954).

O método da Minimização da Entropia Gerada é um método de modelagem e otimização de equipamentos reais que devem sua imperfeição termodinâmica à transferência de calor, transferência de massa e irreversibilidades devido ao escoamento de fluidos, ver BEJAN (1996). Também conhecida como "Otimização Termodinâmica", em Engenharia, onde foi primeiro desenvolvida, ou como "termodinâmica de tempos finitos", em literatura de Física, teve seus primórdios na década de '50 e '60, e estabeleceu-se como área autônoma de pesquisa nos anos 70. Por outro lado, acredita-se (EVANS; ANDRÁS, 1991) que o MEPP não seja válido para condições distantes do equilíbrio por haver uma violação da condição de equilíbrio local (LTE) o que leva a dificuldade - por levantar dúvidas quanto à equação de estado - em se definir precisamente o que significa "geração de entropia". A geração de entropia é calculada em se diferenciando a relação de Gibbs, o que, sem a validade da condição de equilíbrio local aparentemente deixa de ser válido (EVANS; ANDRÁS, 1991).

Neste trabalho de pesquisa, investigar-se-á, para sistemas como esses, à luz da análise exergética, as implicações efetivas em entropia gerada e em seu "irmão", o trabalho perdido, para se tentar validar o princípio acima ou ainda de se investigar 
princípios alternativos a ele, para fenômenos como os deste estudo.

Entropia gerada e trabalho perdido se relacionam através da temperatura de referência $T_{R}\left(\delta W_{\text {perdido }}=T_{R} \delta S_{\text {ger }}\right.$, ou $W_{\text {perdido }}=T_{R} S_{\text {gerada }}$ para $T_{R}$ fixo $)$ (GOUY, 1889; STODOLA, 1903) normalmente tida como sendo a temperatura do ambiente ${ }^{17}$. Para que a temperatura de referência efetivamente represente um vínculo entre a entropia gerada e o trabalho perdido, deve, de forma eficaz, representar o meio, i.e. o estado contra o qual o sistema espera ter um potencial de realização de trabalho.

\subsubsection{O Conceito de chama de pré-mistura reversível}

Conceitualmente, atribui-se a condição de reversibilidade em chamas a KEENAN (1941):

"Para se transformar uma mistura de reagentes em produtos, reversivelmente, precisamos primeiro levar a mistura reversivelmente a um estado em que os reagentes possam coexistir em equilíbrio estável com uma quantidade infinitesimal de produtos - i.e. um estado em que a tendência ao equilíbrio químico tenha desaparecido. Então a mistura poderia ser gradualmente (e reversivelmente) alterada em pressão e em temperatura, ..., enquanto ela segue um caminho de estados mais estáveis e graus progressivamente maiores de combinação."

BERETTA et al. (1992) afirmam que OBERT (1948) levou a idéia um passo adiante:

\footnotetext{
${ }^{17}$ Isso não implica em eleição obrigatória do ambiente como referência, especialmente em sistemas, que, como o deste estudo, interagem pouco com o ambiente, havendo possibilidade de escolha de outras temperaturas de referência.
} 
"Embora não exista método prático de se operar reversivelmente um motor de combustão interna, uma forma teórica pode ser vislumbrada como a proposta por KEENAN (1941). Suponhamos que uma mistura de combustível e ar fosse comprimida isoentropicamente a uma temperatura extremamente alta. (Assumese que a velocidade de compressão seja extremamente alta e que não ocorram reações durante esse período [ou então um catalisador negativo está presente!]). Uma vez atingida essa alta temperatura, reações não ocorreriam significativamente [...] então a mistura poderia ser lenta e isoentropicamente expandida; à medida em que a temperatura cai, as reações progridiriam [...] reversivelmente; e textelp uma quantidade cada vez maior de produtos seria então formada."

Assim, pré-aquece-se a mistura dos reagentes a uma dada temperatura $T_{b}$ e pressão $p_{b}$ enquanto, por algum meio, inibe-se todos os mecanismos de reação. A mistura deve ter a composição preconizada pela condição de equilíbrio químico na dada condição de equilíbrio e de pressão. Uma vez que a mistura tenha sido pré-aquecida a $T_{b}$ e a $p_{b}$, "ligando-se" os mecanismos reativos não terá nenhum efeito na composição pois o equilíbrio químico terá sido atingido. O resfriamento subsequente da mistura reagente irá gradualmente deslocar o equilíbrio e liberar a exergia química do combustível. As discussões originais de KEENAN (1941) e OBERT (1948) apresentam o conceito como bastante teórico devido ao fato que os valores de $T_{b}$ possíveis seriam extremamente altos. BERETTA et al. (1992), no entanto mostram que a princípio uma chama reversível pode se dar a qualquer valor de $T_{b}$. Acredita-se e procurar-se-á demonstrar adiante, que, por questões de necessidade de rendimento exergético unitário (condição de reversibilidade), a temperatura necessária ao longo da chama não seria outra que a sua temperatura de ignição, $T_{i}$. Deve-se lembrar que para se fazer uma análise exergética consistente, a importância de se dispor do conceito de chama reversível é fundamental. Ela seria o pano de fundo da análise exergética. A 
chama reversível representa estados de equilíbrio irrestrito local, i.e. a referência exergética da chama irreversível.

Para finalizar, WEINBERG (1975) conclui que a tendência em pesquisa em combustão como:

"[...] um esforço em se incrementar a controlabilidade, permitindo-nos variar a temperatura da zona de reação, e ainda as velocidades de reação independentemente da razão combustível/ar e também de se variar a velocidade das reações que produzem os poluentes independentemente da taxa de liberação de energia."

Etapa a ser atingida caso essa necessidade venha a poder ser atendida, o conhecimento teórico que leva a poder determinar as características de uma chama reversível é, ver-se-á adiante, condição sine qua non para se poder fazer uma análise exergética consistente de uma chama de pré-mistura.

\section{A chama isotérmica reversível: a caixa de equilíbrio de Van't Hoff}

Combustão isotérmica reversível é idealizada utilizando-se uma caixa de Van't Hoff (HOFF, 1887) (Fig 3.2 KOTAS (1985)) Nesse processo, assume-se que os reagentes e os produtos estão no estado padrão.

Uma caixa de Van't Hoff consiste de um recipiente de volume fixo contendo uma composição de reagentes e de produtos em equilíbrio, sendo respectivamente alimentados e purgados do sistema, em regime permanente e em quantidades estequiométricas. Os reagentes e produtos são alimentados e purgados através de compressores e turbinas isotérmicas, passando por membranas semipermeáveis. Uma mudança infinitesimal nas condições externas é suficiente para inverter o 


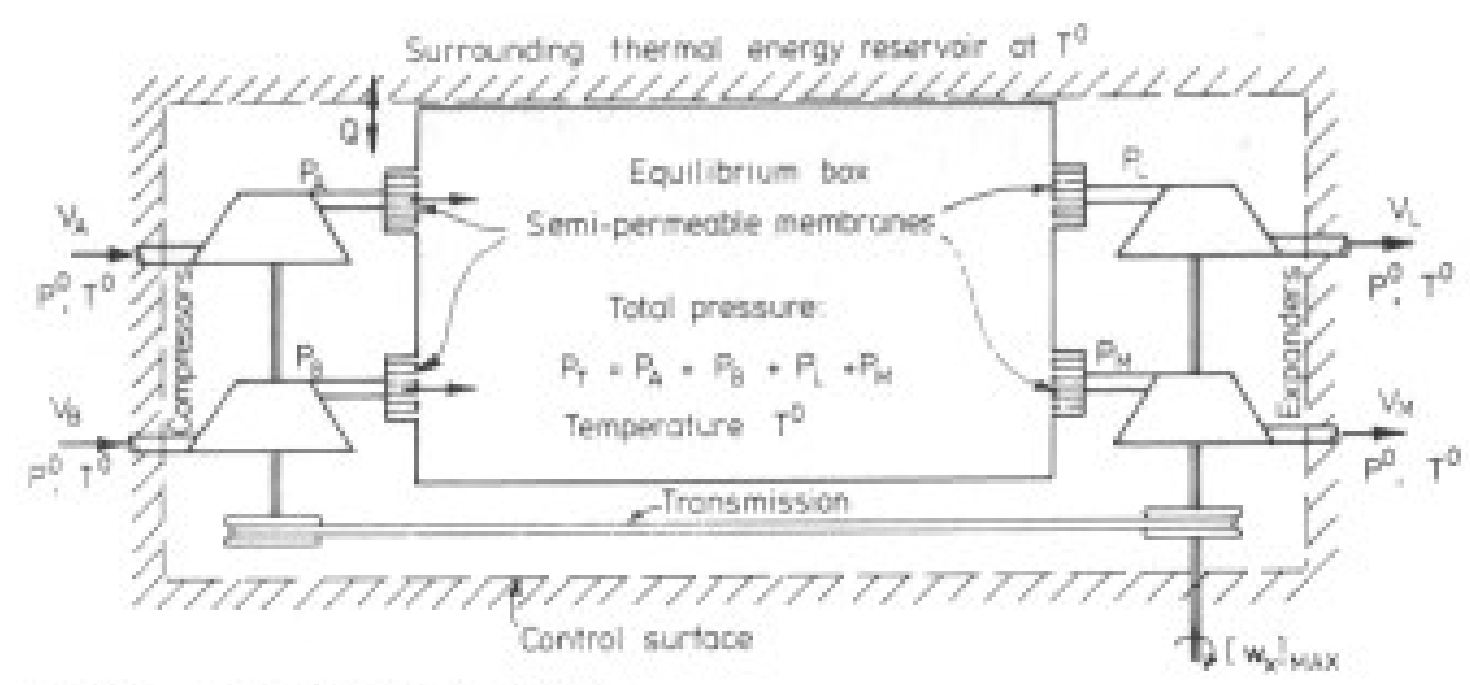

Figura 3.2: Caixa de equil'ibrio de Van't Hoff, extraído de KOTAS (1985)

fluxo.

Como a reação é reversível, máximo trabalho pode ser obtido $\left(\left[\dot{W}_{x}\right]_{M A X}=-\dot{n}_{H_{2}} \Delta g_{R}^{0}\right)$.

A chama isotérmica troca calor com o ambiente $\left(\dot{Q}_{R}=T_{R} \Delta \dot{S}_{R}^{0}\right)$.

\subsubsection{A chama contínua}

\subsection{Chamas contínuas}

Na chama contínua, por não haver saltos, tem-se que $T_{L}=T_{H}=T_{i g n}$, i.e. não há exergia térmica - pois a temperatura das fatias é a mesma da temperatura de referência - apenas exergia química, que diminui com o progresso da chama. 
A cada temperatura, tem-se:

$$
\delta \dot{W}_{\text {perd }}=-\delta \dot{n}_{H_{2}} \Delta g_{i g n}^{0}
$$

ou ainda:

$$
\delta \dot{S}_{g e r}=-\delta \dot{n}_{H_{2}} \frac{\Delta g_{i g n}^{0}}{T_{i g n}}
$$

Toda a exergia química se transforma em trabalho perdido. O trabalho reversível é totalmente perdido, daí a condição de irreversibilidade máxima.

Abordagens termodinâmicas que presumem o equilíbrio contínuo não são capazes, via de regra, de prever o perfil de espécies e a temperatura de uma chama de prémistura: prevê-se reação completa a temperaturas baixas bem como o aumento da quantidade de reagentes com o aumento da temperatura, contrário ao que se verifica na prática, conforme mostra a figura 3.3 .

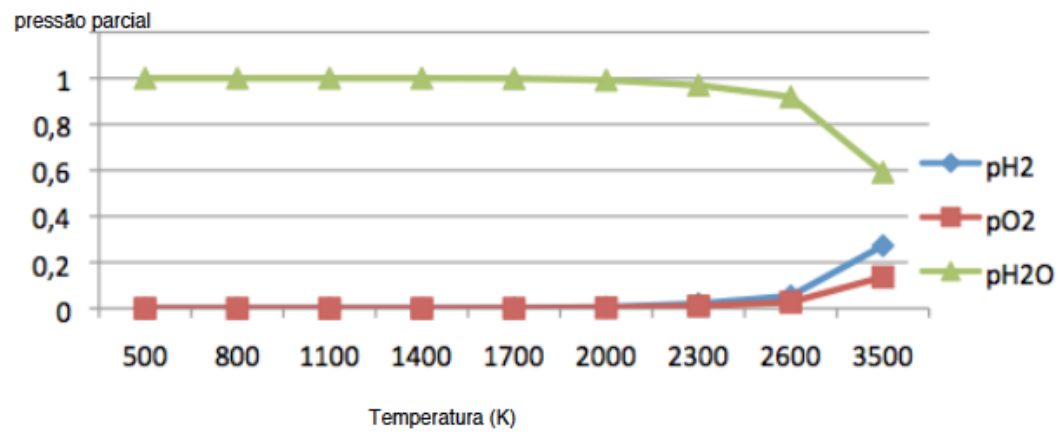

Figura 3.3: Frações molares de $\mathrm{H}_{2}, \mathrm{O}_{2}$ e $\mathrm{H}_{2} \mathrm{O}$ no caso de equilíbrio contínuo 


\section{Capítulo 4}

\section{Metodologia: Métodos e}

\section{Materiais}

Quer-se modelar uma chama de pré-mistura de $\mathrm{H}_{2}+\mathrm{O}_{2}$ de duas fatias em que toda ou parte da exergia química é convertida em exergia física. Há duas situações: o caso reversível e o caso de irreversibilidade estacionária.

Vê-se que a brecha da conexão entre a termodinâmica e a CAo existe: em se maximizando o trabalho perdido. Essa brecha será explorada para uma chama de duas fatias.

A consequência desse fato é a de que não se pode resolver a chama considerando apenas as partes; a dinâmica local seria função do sistema como um todo. 


\subsection{Métodos}

\subsubsection{A chama objeto do presente estudo}

A chama objeto do presente estudo foi escolhida para permitir que se isolasse, em uma primeira instância, o processo reativo - o que maior contribuição fornece à geração de entropia (NISHIDA; TAKAGI; KINOSHITA, 2002) - de demais processos que viessem a contribuir para a geração de entropia em chama. Neste primeiro momento pretende-se investigar se a termodinâmica clássica pode nos auxiliar a modelar esses processos reativos.

\section{A chama de pré-mistura}

O mecanismo de controle, ou limitante, em uma chama de não pré-mistura é fluido-dinâmico. Sua escolha implicaria em se ter de modelar o processo fluidodinâmico prioritariamente ao se almejar modelar a chama. A escolha da chama de pré-mistura em detrimento de uma chama de não pré-mistura se dá pelo motivo de a chama de pré-mistura ser limitada fisicamente pelos processos químicoreativos que se processam ao longo dela, esses, supostamente passíveis de uma investigação de modelagem do tipo termodinâmico.

\section{A chama adiabática}

Os processos reativos ocorrem somente na direção do escoamento, não havendo troca de calor nem de espécies no contorno da chama com o ambiente externo. Essa hipótese se justifica pois a taxa de reação na direção ortogonal ao escoamento são insignificantes em relação às taxas de reação que ocorrem na direção 
do escoamento, devido às variações de temperatura que se concentram nessa direção. O sistema se comporta portanto, por hipótese, como se estivesse fechado lateralmente. Na entrada suporemos ter condições de contorno fixas (temperaturas e frações molares das espécies químicas). Na saída consideraremos a temperatura variável e a fração molar fixa.

Optando-se pela condição de adiabaticidade externa, pode-se restringir a análise de uma chama de pré-mistura ao que ocorre internamente a ela, i.e. foca-se no processo reativo sem interações de troca térmica com o meio que poderiam, por alterar as temperaturas de chama, camuflar os processos reativos ocorrendo em seu interior. Longitudinalmente - ou internamente (na direção de propagação de chama), no entanto, há troca de calor, que se dá entre os subsistemas -

considera-se a chama um sistema composto. Esta hipótese está ancorada no fato de que a superfície lateral - ao longo da espessura da chama - é muito delgada, tipicamente na ordem de milímetros $(\mathrm{mm})$.

Dadas essas duas simplificações, o sistema é considerado isolado lateralmente. É importante notar a diferença entre um reator adiabático e uma chama adiabática. Enquanto aquele tem paredes isoladas, permitindo a condição adiabática, esta não as têm, sendo portanto uma abstração física; i.e. um construto.

\section{A chama composta de gases perfeitos}

Por ser a pressão a que trabalham baixas e as temperaturas altas, é realista se considerar que os componentes gasosos de chamas de pré-mistura sejam gases perfeitos, com equações de estado conhecidas de forma analítica. 


\section{A chama de escoamento ideal}

Há, em chamas turbulentas de pré-mistura, uma interação turbulência-processo reativo, e este tem duas vias, i.e. o processo reativo influencia a turbulência e esta influencia o processo reativo. Este acoplamento se dá pelos significativos aumentos em massa específica e de viscosidade - devido principalmente aos grandes aumentos em temperatura em chama - e que influenciam as características de turbulência. Efeitos na viscosidade se fazem sentir principalmente nas escalas menores de turbulência, onde ocorrem as reações.

Em chamas turbulentas de pré-mistura, há necessidade, pois, de se desacoplar, para fins de análise, esses dois fenômenos, determinando-se a taxa média de reação e os parâmetros que, no modelo utilizado, identifiquem a turbulência do escoamento, especialmente às energias de menor escala (escalas de Kolmogorov). Isso dá origem à necessidade de se resolver então conjuntos de equações diferenciais adicionais para o fechamento do problema, introduzindo - e propagando imprecisões inerentes aos modelos (invariavelmente fenomenológicos) utilizados, por exemplo.

O número de equações necessárias para representar este acoplamento depende dos modelos utilizados para representar o fenômeno reativo e a turbulência ao longo da chama. Em relação ao problema envolvendo chamas laminares introduzse, assim, um complicador adicional. O desacoplamento efetivo desses dois fenômenos é função da exatidão com que os modelos utilizados representam o fenômeno real. Já que as equações adicionais resultam de modelos cujo conteúdo é, via de regra, fenomenológico, representam de forma mais ou menos confiável, o fenômeno em questão.

Nas chamas laminares, embora não haja esse complicador, continua havendo uma 
destruição de exergia no escoamento devido à dissipação que ocorre por conta da viscosidade. Para se evitar esse complicador, tem-se que levar isso em conta. Optou-se, nesse instante, pela escolha de uma chama em que prevaleça um escoamento ideal: sem viscosidade, pois. Isso permitirá que se concentre a atenção no principal foco de irreversibilidades, que são os processos reativos.

\section{A chama unidimensional}

A escolha de uma chama unidimensional, ao mesmo tempo em que simplifica a confecção do modelo - não introduzindo complicadores próprios da introdução de uma segunda dimensão -, facilita a sua validação experimental. Além disso, perfis experimentais oriundos de chamas unidimensionais estão amplamente disponíveis na literatura existente.

\section{As fatias são reatores com composição fixa}

Cada fatia é considerada como sendo um reator com composição fixa, i.e. não ocorre reação nas fatias. Isso nos permite fazer uma análise concentrada para cada fatia.

$\tau_{c . c .} \rightarrow \infty$

A condição da interface, ou de ignição (c.c.) é considerada como sendo fixa $\left(\tau_{c . c .} \rightarrow \infty\right)$. Por esse motivo, podemos considerar regime permanente. Considerase a inércia do subsistema fatias pequena quando comparada à inércia da condição de ignição (interface). 
A chama $\mathrm{H}_{2}-\mathrm{O}_{2}$

A relevância em pesquisa da chama $H_{2}-O_{2}$ se dá porque ela é a chama que envolve reações com o menor número de espécies químicas. Além disso, a cinética de oxidação de $\mathrm{H}_{2}-\mathrm{O}_{2}$ seguido pela incorporação do mecanismo químico de $\mathrm{CO}$, por exemplo, é importante em qualquer modelo detalhado de combustão de hidrocarbonetos, a começar pelo metano, constituindo, segundo GARDINER (2000), o cerne dos 4 mecanismos de interação, quais sejam ainda, oxidação de $\mathrm{CH}_{2} \mathrm{O}$ e de $\mathrm{CH}_{4}$, que, ainda, como dissemos, fazem parte dos mecanismos presentes em hidrocarbonetos de cadeia maior. Daí sua importância.

Assim, chega-se à chama objeto deste estudo: uma chama de $\mathrm{H}_{2}-\mathrm{O}_{2}$, de pré-mistura, de gases perfeitos, externamente adiabática, de escoamento ideal e unidimensional.

\section{A chama de duas fatias}

A chama de duas fatias é composta de uma fatia a temperatura baixa, uma fatias a temperatura alta e uma superfície de ignição entre elas, onde ocorre uma reação de combustão completa de um passo. Vide figura 4.1 .

\subsubsection{O estado de referência}

\section{Qualificando o estado de referência}

A chama (e seus fenô menos internos), via de regra não interage quimicamente com o ambiente externo $\left(p_{0}, T_{0}, \mu_{0 i}\right)$. Como para ser quantificada, a exergia 


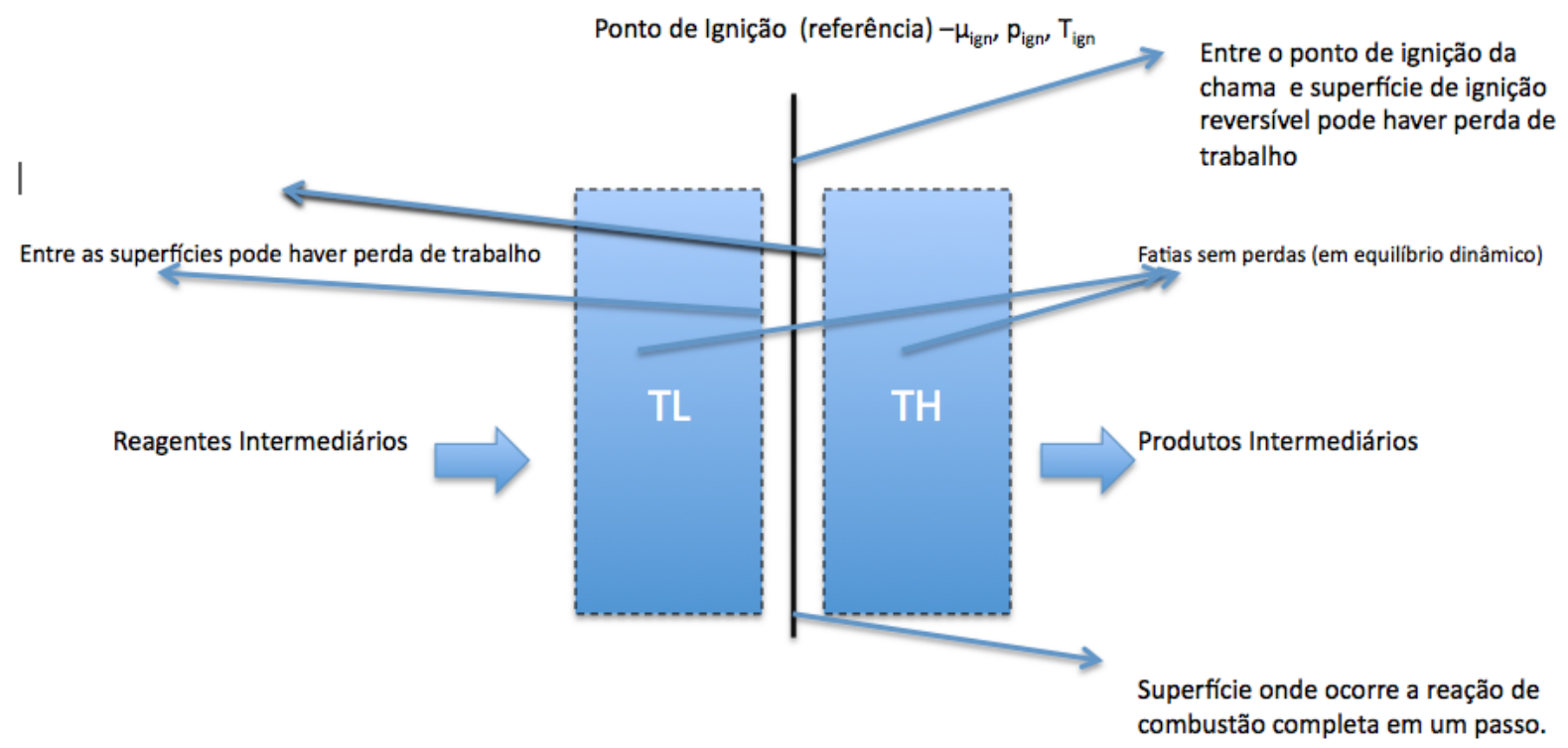

Figura 4.1: A chama de duas fatias

depende do meio, e o ambiente externo não é o meio para os fenômenos internos da chama, para quantificar a exergia da chama, precisamos buscar um novo meio que seja adequado.

Nos saltos da CAo, há um ponto singular. São os pontos críticos. Estão em equilíbrio. Neles ocorrem as mudanças de fase. São candidatos naturais a referência $\left(p_{i g n}, T_{i g n}, \mu_{i g n_{i}}\right)$ pois, além de estarem em equilíbrio, não estão em "dead state", o que permite a evolução do sistema rumo a outros pontos críticos, provendo ao sistema uma característica dinâmica.

A pressão em uma deflagração pode ser considerada constante. A pressão de referência será portanto $p_{0}$.

A figura 4.2, mostra essa diferença.

O ambiente local é usado como referência, por exemplo, na avaliação de de- 


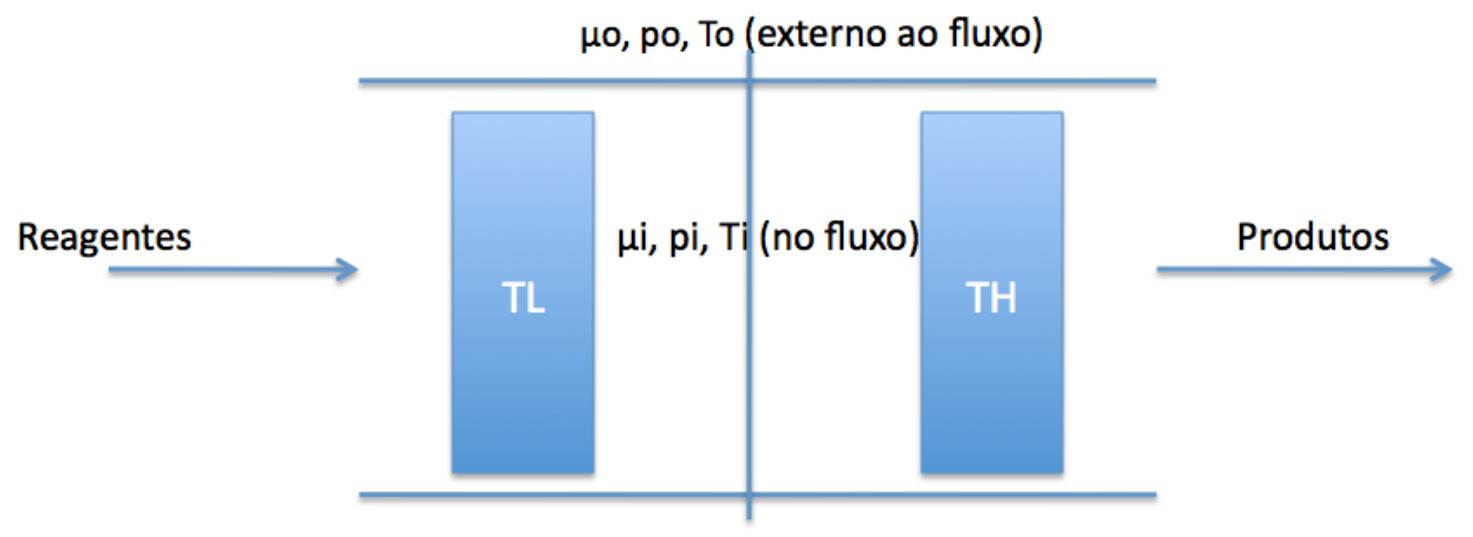

Figura 4.2: A referência exergética

sempenho no caso do cálculo da exergia em aeronaves (também chamada de referência variável, obtida de acordo com as condições de vôo) ROTH (2000). Prefere-se a referência variável ao ambiente de solo pois a exergia em relação ao ambiente de solo não se realiza sob condições naturais, em situação de vôo. A diferença nos cálculos de exergia monta a $2 \%$.

No caso de se avaliar o potencial exergético de uma edificação, pode-se imaginar que o ambiente seja uma referência variav́el devido à existência de variações diárias e sazonais na condição do ambiente, como descrito em TORIO (2009).

Deve-se enfatizar, no entanto, que a situação de ambos os casos descritos acima são distintas da situação de chama pois não havendo interferência externa no funcionamento da chama, que se dá de forma natural, pode-se intuir que esta seja passível de formulação de um princípio de otimização.

\section{Quantificando o estado de referência no quesito temperatura}

A escolha do estado de referência, que é arbitrária, foi feita de tal forma que a condição de estacionaridade do trabalho perdido pudesse ser imposta, permi- 
tindo à chama ser completamente determinada ao otimizar os graus de liberdade existentes, i.e. possibilita-se a determinação da referência.

O ponto onde as condições de estacionariedade do trabalho perdido internamente à chama foram satisfeitos pode então ser encontrado e foi chamado de ponto de ignição $\left(x_{i g n_{i}}, T_{i g n}\right)$. Esse ponto foi considerado como sendo a referência efetiva, ou meio, da chama de duas fatias.

Deve-se notar que a exergia dentro da chama, referenciada ao ponto de ignição é complementar à exergia do ponto de ignição relativa ao ambiente, $T_{0}, \mu_{i_{0}}$.

\subsubsection{Os subsistemas e o ambiente}

Considerou-se um dos subsistemas como sendo a interface, onde ocorre a reação completa de um passo. O outro subsistema são as duas fatias, ou reservatórios finitos. O ambiente, tudo externo. No caso da chama reversível, o processo é considerado como sendo internamente reversível.

O modelo é uma adaptação do "hot brick problem" (ou "problema do tijolo aquecido"), vide figura 4.3. Nele, pretende-se extrair o máximo trabalho de dois tijolos ou reservatórios finitos a temperaturas distintas. Para isso, coloca-se uma máquina térmica reversível entre eles. À medida em que o calor é transferido da fonte quente para a máquina térmica, a fonte quente tem sua temperatura reduzida. O calor rejeitado pela máquina ao reservatório a temperatura baixa faz com que este reservatório tenha sua temperatura incrementada. O processo prossegue até que a temperatura dos dois reservatórios se igualem. Um trabalho máximo é produzido.

A figura 4.4 mostra o subsistema caixa de equilíbrio de Van't Hoff, onde o sub- 


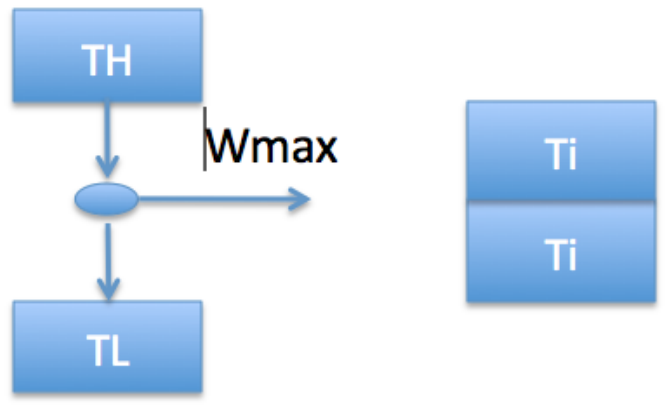

Figura 4.3: O problema do tijolo aquecido

sistema realiza uma taxa de trabalho equivalente a $-\Delta \dot{G}_{R}^{0}$ sobre os reservatórios devido a uma reação reversível a $T_{R}$ (reagentes $\rightarrow$ produtos, ambos no estado padrão a $T_{R}$ ). A taxa de calor trocado devido à reação reversível é igual a $\dot{Q}_{R}=T_{R} \times \Delta \dot{S}_{R}^{0}$ sendo trocado com os reservatórios.

A figura 4.5 mostra a taxa de troca de calor entre a interface e os reservatórios, $-\dot{Q}_{R}$. A taxa de exergia química da interface, $\Delta \dot{G}_{R}^{0}$, é integralmente convertida em taxa de exergia térmica dos reservatórios (taxa de exergia térmica dos reagentes (temperatura varia de $T_{R}$ a $T_{L}$ ) e taxa de exergia térmica do produto $\left(H_{2} O\right.$, cuja temperatura varia de $T_{R}$ até $\left.\left.T_{H}\right)\right)$. Os subsistemas são simétricos em relação às interações. À medida em que essa conversão ocorre, os reservatórios têm aumento em sua taxa de exergia, indo do estado inicial ( $H_{0}$ e $\left.L_{0}\right)$ ao estado final $\left(H_{1}\right.$ e $\left.L_{1}\right)$. As fatias têm sua temperatura variando por conta do trabalho recebido da interface. O movimento simula um problema do tijolo aquecido invertido.

As figuras 4.4 e 4.5 mostram as duas fatias bem como as variáveis necessárias para se calcular a taxa de exergia e a potência perdida na chama. 


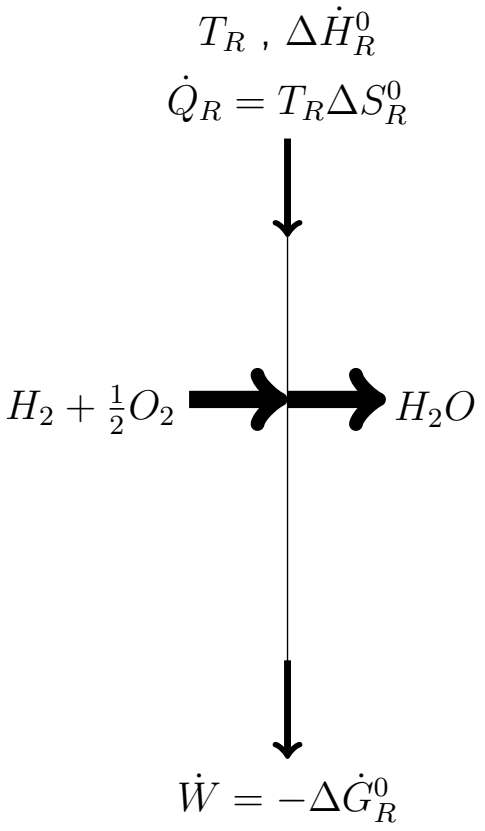

Figura 4.4: Figura mostrando a interface, ou caixa de equilíbrio de Van't Hoff.

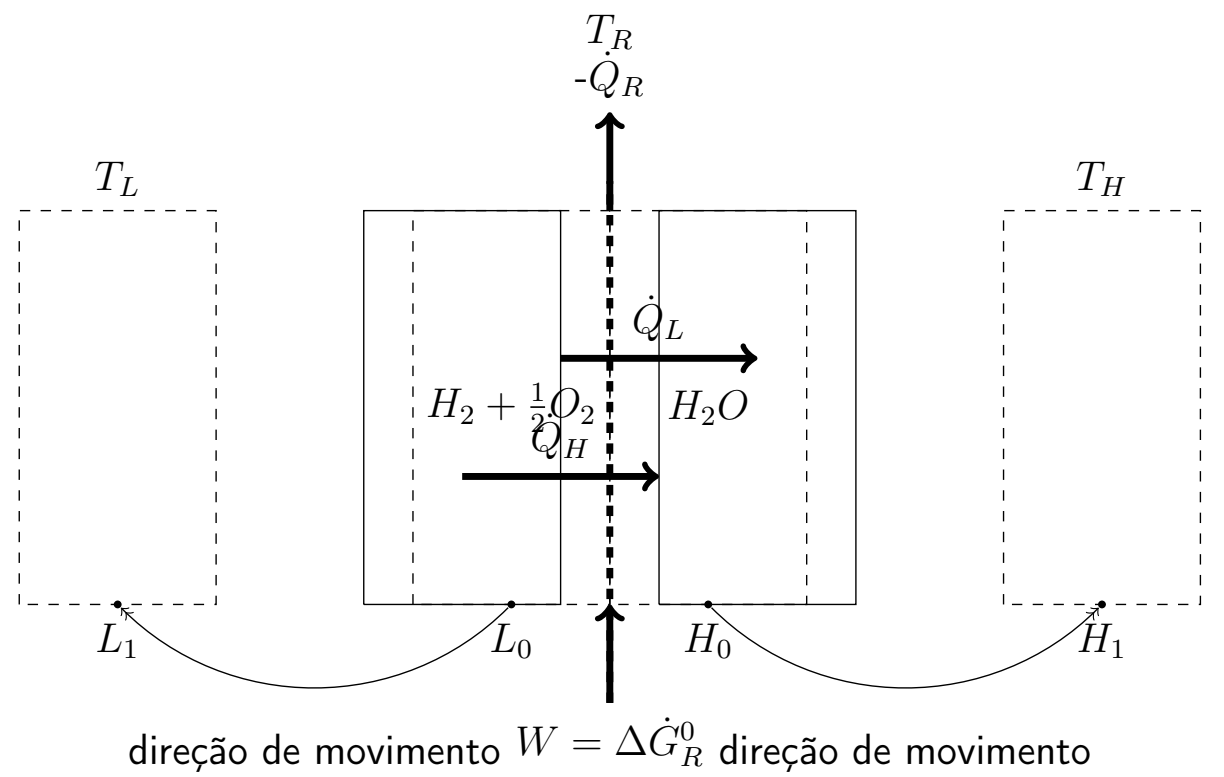

Figura 4.5: Figura mostrando os reservatórios, com estado incicial e final (pontilhado), bem como o estado intermediário (com $\dot{Q}_{L}$ e $\dot{Q}_{H}$ ). 


\subsubsection{Método para se determinar a chama adiabática reversível}

Para a chama adiabática reversível, procurou-se igualar a exergia química à exergia térmica por um lado, e por outro lado, utilizando a segunda lei, para a chama adiabática reversível, considerou-se o sistema como sendo internamente reversível.

Há duas componentes de taxa de exergia na chama: taxa de exergia física e taxa de exergia química. Não há taxa de exergia devido a transferência de calor pois a temperatura de fronteira é a mesma que a temperatura de referência $\left(\dot{B}_{\text {transf.calor }}\right.$ $=0)$.

\subsubsection{Método para se determinar o ponto estacionário da chama adiabática irreversível}

O trabalho perdido no caso descontínuo é menor que o trabalho perdido no caso contínuo, que é máximo. Ele é menor pela parcela da exergia física, presente no caso descontínuo (mas ausente no caso contínuo) e equivalente a:

$$
\dot{B}_{\text {term }}=\dot{n} c_{p}\left(T_{H}+T_{L}-2 T_{i g n}\right)-\dot{n} c_{p} T_{i g n} \ln \frac{T_{H} T_{L}}{T_{i g n}^{2}}
$$

Há espaço para modelagem termodinâmica de uma chama irreversível utilizando a análise exergética?

1) Vimos que a taxa de trabalho perdido no caso contínuo já é ótimo (é o máximo absoluto) e não resolve. 
2) Alternativa: tentar extremar a taxa de trabalho perdido para o caso descontínuo e obter o máximo relativo.

3) Os modelos representam paradigmas distintos. A promoção de variação de temperatura do primeiro é por taxa de troca de calor e do segundo é por receber poteência.

No caso da chama adiabática irreversível de duas fatias, procuramos extremar a taxa de trabalho perdido em relação ao ponto de ignição (eq. 4.2) :

$$
\dot{B}_{\text {quim }}-\dot{B}_{\text {term }}=\dot{W}_{\text {perdido }}
$$

O objetivo era de se obter uma expressão que tivesse como ponto estacionário a composição bem como a temperatura da superfície de ignição.

Para se encontrar o ponto estacionário da taxa de trabalho perdido internamente, há que se formular o Lagrangeano dessa função. A necessidade do Lagrangeano se dá pois a função taxa de rabalho perdido internamente conta com uma restrição, dada pela Primeira Lei (chama adiabática). Uma vez que se constrói o Lagrangeano, passa-se então a construir a matriz Hessiana aumentada, se determina se a matriz é positivo definida (tem-se um mínimo) ou negativo definida (tem-se um máximo) ou nenhuma das duas (ponto sela).

\subsubsection{Comentários}

Fazendo uso da modelagem termodinâmica convencional (uma e única fase), não há, via de regra, tempo hábil para que se estabeleça o equilíbrio ao longo de toda a chama quando se inclui transporte advectivo, como demonstram amplamente 
as tentativas, sem sucesso, de modelagem termodinâmica, sugerindo ora:

(i) uma inépcia da abordagem termodinâmica, ora

(ii) que se faz necessário rever a forma como se modela termodinamicamente o fenômeno.

O presente estudo permitirá construir os fundamentos para que se determine em qual dessas duas condições se está.

Servir-se-á do teorema de Duhem (DUHEM; NEEDHAM, 2011);

Para qualquer sistema fechado formado inicialmente por espécies químicas com quantidade de massa especificada, o estado de equilíbrio é completamente determinado quando são fixadas quaisquer duas variáveis independentes.

O objetivo principal deste estudo, dessa forma, será o de se identificar se a hipótese de equilíbrio local é válida para uma chama. Para isso, deve-se:

... encontrar a composição de um sistema que alcança o equilíbrio a partir de um estado inicial com quantidades conhecidas das espécies reagentes, quando duas outras variáveis independentes - temperatura $(T)$ e pressão $(p)$, por exemplo - são especificadas.

Ao se definirem a quantidade inicial de reagentes, com a sua temperatura e a pressão bem determinadas, o sistema contemplará os dois graus de liberdade (fixados, ab initio) preconizados pelo teorema acima. Buscará, então, extremar a taxa de trabalho perdido da chama.

Entre as fatias e a descontinuidade, e entre a interface da chama irreverível e da chama reversível concentra-se a taxa de geração de entropia e o potência perdida 
internamente. 


\section{Capítulo 5}

\section{Resultados e Discussão}

$\mathrm{O}$ ambiente externo tem possibilidade de contato quase que exclusivamente com os reagentes puros ou com os produtos da reação completa (as reações ocorrem via de regra, quase que exclusivamente na direção do escoamento - que é onde se dá o mecanismo das reações - ficando as possíveis reações na direção perpendicular ao escoamento, sem ocorrer i.e. o tempo para que elas ocorram na direção perpendicular ao escoamento é muito maior do que o tempo para que elas ocorram na direção do escoamento), assim, a referência externa à chama (o meio a $T_{0}$ e a $\mu_{0}{ }^{1}$ ) permitiria trabalhar apenas com informações da transformação total (reagentes e produtos, referenciando o meio externo); os componentes químicos intermediários de uma chama de pré-mistura praticamente não interagem quimicamente com o ambiente externo (análise de "caixa preta"). Se se criassem processos ideais que levassem as espécies intermediárias ao equilíbrio com o meio ambiente externo, descaracterizar-se-ia a análise, pois não é o que ocorre em uma chama real.

\footnotetext{
${ }^{1}$ o potencial químico das espécies no estado de referência.
} 
Não tendo como se incluir os elementos intermediários em uma análise com referência externa de chama, uma análise desse tipo manteria a chama na condição de "caixa preta", sem acesso à sua estrutura (essa impossibilidade de acesso é em última instância o que se pretende questionar, nesta análise).

Uma referência interna, por outro lado, permite que se trabalhe com parâmetros internos à chama (temperaturas e frações molares de espécies intermediárias), segundo um modelo de chama utilizado e assim, abre a possibilidade de se determinar, o que é um dos objetivos desta pesquisa, uma estrutura interna.

\subsection{Ponto de ignição como referência}

Por definição a potência perdida é dada pela equação 4.2 .

onde $T_{R}$ é uma temperatura de referência. Como $\dot{S}_{g e r}$ é maior ou igual a zero, a taxa de trabalho perdido será sempre positiva ou nula. É importante notar-se que $\dot{S}_{g e r}$ depende exlusivamente do grau de irreversibilidade termodinâmica do processo em questão, no entanto, a taxa de trabalho perdido é uma quantidade relativa: depende da escolha da temperatura de referência, $T_{R}$ RATHAKRISHNAN (2005).

O ponto de ignição neste modelo, é, localmente, a "singularidade" que permeia as fatias. Sendo a referência local, esses pontos são determinados de tal forma que o trabalho perdido internamente na chama seja máximo. 


\subsubsection{A exergia de ignição}

Rearranjando a equação 4.2 , tem-se:

$$
\dot{B}_{\text {quim }}-\dot{W}_{\text {perdido }}=\dot{B}_{\text {term }}
$$

A potência perdida reduz a taxa de exergia química disponível. O mecanismo responsável por essa redução da taxa de exergia parece estar ligado à taxa de exergia necessária para que a ignição ocorra. Nesse cenário, o inverso da potência perdida $\left(-\dot{W}_{\text {perdido }}\right)$ poderia ser chamado de taxa de exergia de igniçãd ${ }^{2}$, sendo esta nula para reações reversíveis.

\subsection{Chama adiabática de equilíbrio (chama de uma fatia)}

Se se isolar uma chama de pré-mistura, as espécies presentes entram em equilíbrio, i.e. decaem para o que chamamos de "chama adiabática de equilíbrio", ou ponto morto (interno) da chama.

Uma vez que se retire essa chama do isolamento, ela decai e entra em equilíbrio com o meio ambiente. A exergia total de uma chama pode ser assim vista como tendo duas componentes; a exergia "interna", e a exergia "externa" (em relação ao meio ambiente).

\footnotetext{
${ }^{2}$ no contexto de chama termodinâmica, a taxa de exergia de ignição lembra o conceito cinético-químico de energia de ativação e se caracteriza pelo taxa de trabalho realizado sobre o sistema para que a ignição ocorra.
} 
A chama adiabática de equilíbrio também pode ser denominada de chama de velocidade de chama nula pois não há conversão líquida de reagentes em produtos. O sistema seria, para todos os efeitos, isolado.

Adotou-se, para tanto, o modelo descrito em WINTERBOTTOM; KING (1999) de um reator isolado, em que ocorre uma reação exotérmica, em condições de equilíbrio. A chama de equilíbrio seguirá esse modelo de reator, já que ela é adiabática e os reagentes estão em equilíbrio químico com os produtos. De início usar-se-á, supondo equilíbrio, a reação global:

$$
\mathrm{H}_{2}(g)+1 / 2 \mathrm{O}_{2}(g) \rightleftharpoons \mathrm{H}_{2} \mathrm{O}(g)
$$

Para que se obtenha a chama de equilíbrio de $\mathrm{H}_{2}+\mathrm{O}_{2}$, precisa-se calcular a conversão de equilíbrio de $H_{2}$ no reator e então se determinar a que conversão de equilíbrio corresponde a condição de adiabaticidade.

Sabendo-se que a segunda lei fornece a equação para a condição de equilíbrio:

$$
\ln K_{0}=-\frac{\Delta G^{0} R}{R T_{0}}
$$

Tem-se, a cada temperatura, para uma dada $K_{e q}$, uma conversão diferente $X_{H_{2}}$, de $\mathrm{H}_{2}$.

$$
\ln \frac{K_{e q}}{K_{0}}=-\frac{\Delta H^{0} R}{R}\left(\frac{1}{T_{e q}}-\frac{1}{T_{0}}\right)
$$

Com:

$\Delta g_{R}^{0}=-228,6 \frac{k J}{\text { mol }_{\text {comb }}}$ 
$\Delta h^{0}{ }_{R}=-241,8 \frac{\mathrm{kJ}}{\text { mol }_{\text {comb }}}$

$R=8,314 \frac{\mathrm{J}}{\mathrm{molK}}$

A equação 5.3, de Van't Hoff, aparece da relação termodinâmica entre $\Delta G$ a $\Delta H$ (onde $\Delta H$ é considerado constante para variações pequenas de temperatura, e $\Delta G$ é fortemente dependente da temperatura) e nos fornece a relação $K_{e q} \times T_{e q}$. Daí conseguimos visualizar a conversão de equilíbrio em função da temperatura para reações exotérmicas, como mostra a figura 5.1 .

A primeira lei, além disso, garante que a perda de entalpia devido à exotermicidade da conversão se iguala ao ganho de entalpia recebido pela mistura em equilíbrio, que tem então sua temperatura elevada de $T_{0}$ a $T_{a d_{e q}}$, de forma que a entalpia total não sofra alteração:

$$
H_{\text {final }}-H_{\text {inicial }}=n_{H_{2}} X_{H_{2}} \Delta H_{R}^{0}+\int_{T_{0}}^{T_{a d_{e q}}} \sum_{i} n_{i} \bar{c}_{p i} d T=0
$$

Onde $i$ são os componentes em equilíbrio adiabático.

Dessa forma, tem-se duas incógnitas, $K_{e q}$ (ou $X_{H_{2_{e q}}}$ ) e $T_{a d_{e q}}$, com duas equações (dadas pela primeira e pela segunda lei, mais uma relação termodinâmica), 5.3 e 5.4, respectivamente. Por iteração pode-se então obter o grau de conversão $X_{H_{2}}$ e a $T_{a d_{e q}}$ e assim toda a composição da chama de equilíbrio (vide gráfico 5.2).

Ao se efetuar esse procedimento constata-se que a temperatura de equilíbrio adiabático é de em torno de $2100 \mathrm{~K}$, abaixo do valor da temperatura de chama adiabática (3500K). Isso se deve ao fato de o equilíbrio estar muito deslocado para o lado dos produtos. 


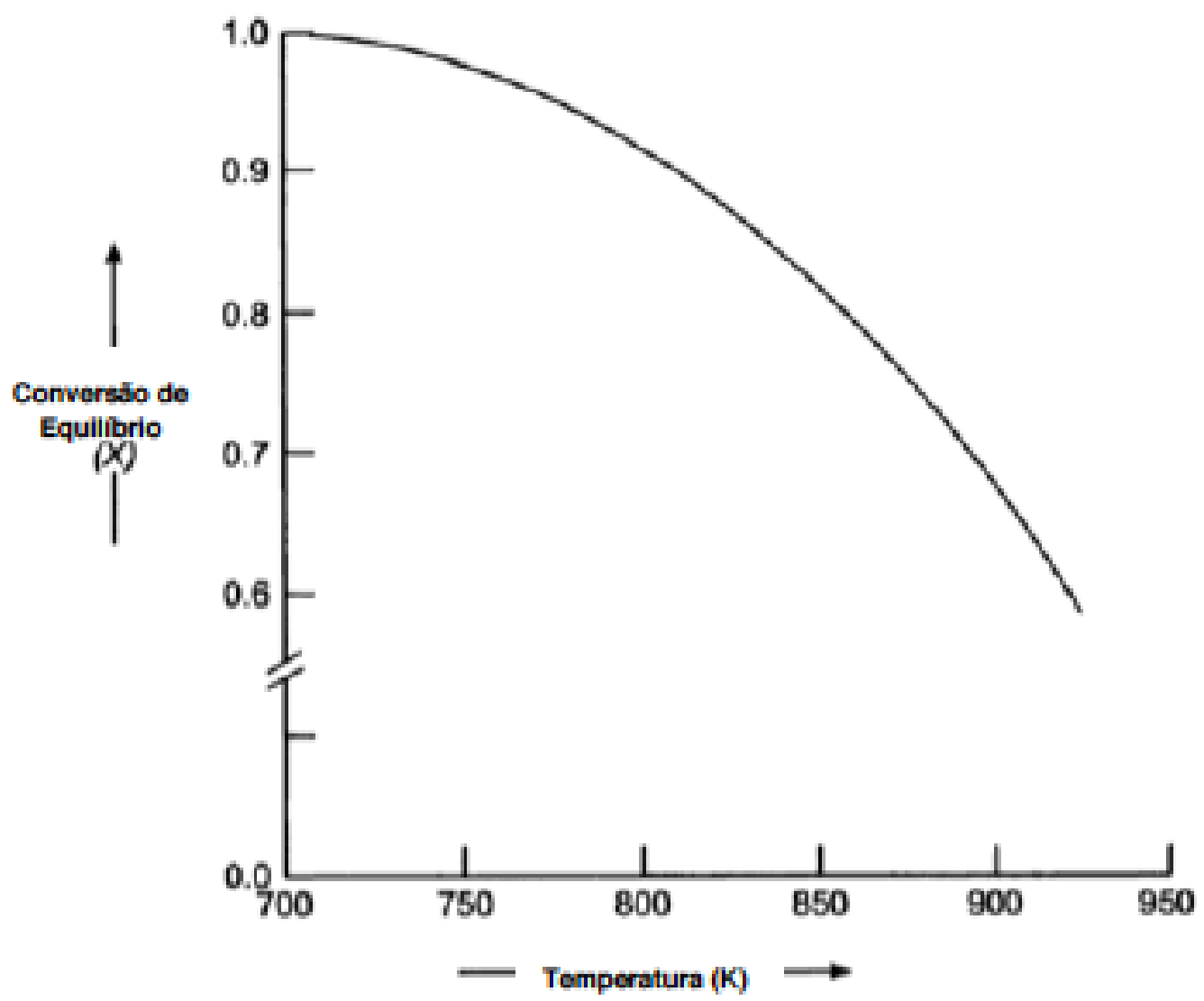

Figura 5.1: Gráfico do grau de conversão em equilíbrio em função da temperatura de equilíbrio, segundo WINTERBOTTOM; KING (1999).

\subsection{Chama adiabática reversível de duas fa- tias}

Da chama de equilíbrio para a chama reversível descrita em 3.5.4, para o modelo aqui descrito de chama adiabática reversível, passa-se de um modo de combustão estática a um modo dinâmico de chama, com temperatura variável, mais próximo 


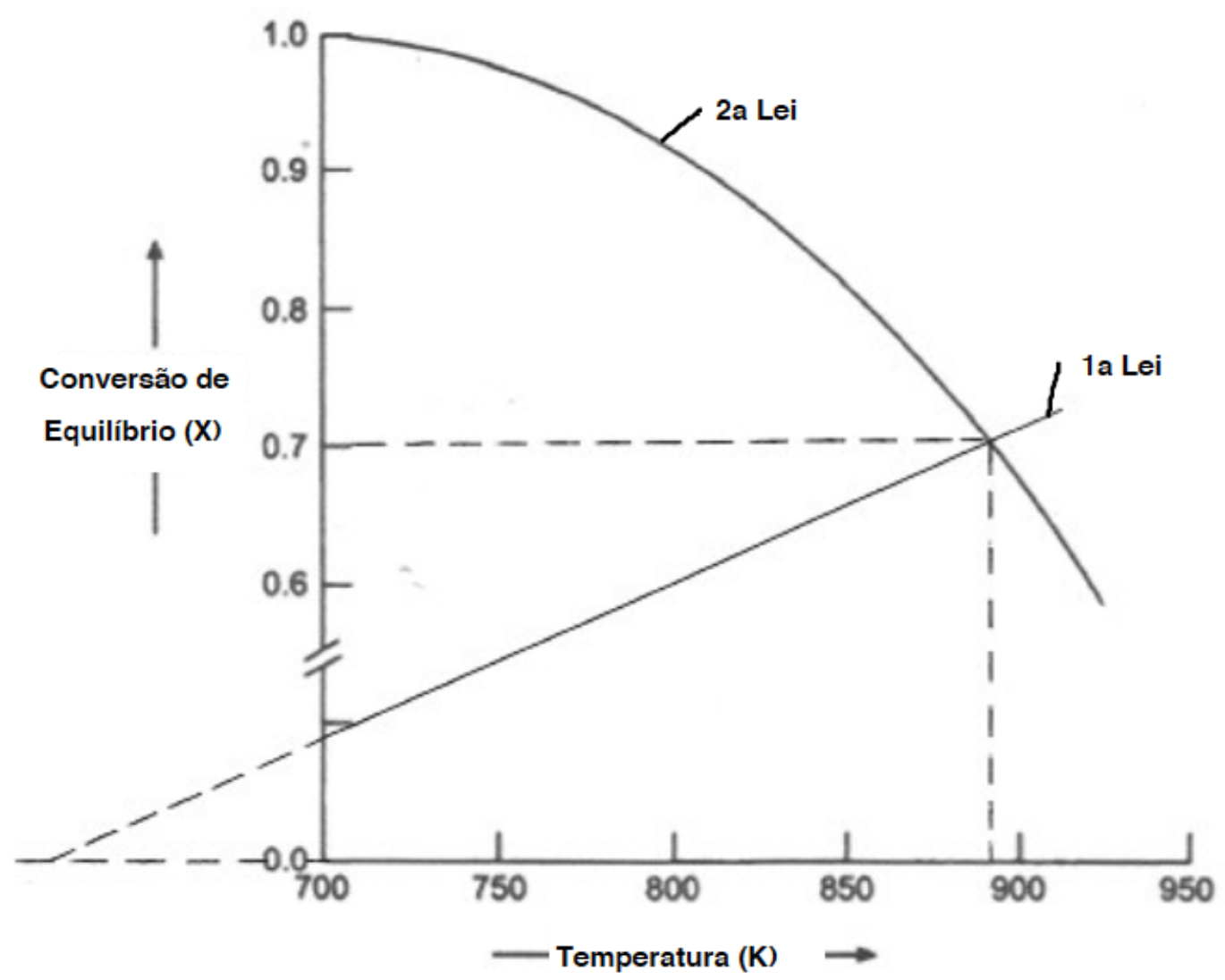

Figura 5.2: Gráfico mostrando o grau de conversão adiabática de equilíbrio, segundo WINTERBOTTOM; KING (1999).

ao comportamento de uma chama real.

Voltando às figuras 4.4 e 4.5 , para se determinar a chama reversível de duas fatias deve-se resolver as equações para a Segunda Lei, considerando reversibilidade interna e a equação da conservação de exergia: 
Para um processo adiabático reversível:

$$
\Delta \dot{S}_{\text {sistema }}=\Delta \dot{S}_{\text {interface }}+\Delta \dot{S}_{\text {reservatorios }}=0
$$

Onde para a interface, onde ocorre a reação reversível:

$$
\Delta \dot{S}_{\text {interface }}=\dot{n}_{H_{2}} \Delta s_{R}^{0}
$$

E para as fatias, que têm suas temperaturas variando desde $T_{R}$ :

$$
\Delta \dot{S}_{\text {reservatorios }}=\dot{n}_{\text {reag }} \bar{c}_{p_{\text {reag }}} \ln \frac{T_{L}}{T_{R}}+\dot{n}_{\text {prod }} \bar{c}_{p_{\text {prod }}} \ln \frac{T_{H}}{T_{R}}
$$

Onde:

$\Delta \dot{S}_{\text {interface }}$ é a taxa de variação de entropia na interface;

$\Delta \dot{S}_{\text {reservatorios }}$ é a taxa de variação de entropia dos reservatórios;

Com a condição que a perda de entalpia da interface deve ser igual ao ganho de entalpia das fatias:

$$
\dot{n}_{H_{2}} \Delta h_{R}^{0}+\dot{n}_{\text {reag }} \bar{c}_{p_{\text {reag }}}\left(T_{L}-T_{R}\right)+\dot{n}_{\text {prod }} \bar{c}_{p_{\text {prod }}}\left(T_{H}-T_{R}\right)=0
$$

Supondo $\dot{n}_{\text {reag }} \bar{c}_{p_{\text {reag }}}=\dot{n}_{\text {prod }} \bar{c}_{p_{\text {prod }}}=\dot{n} c_{p}$, podemos obter uma expressão qualitativa que resume as características do ponto de ignição. Temos:

$$
\Delta \dot{S}_{\text {reservatorios }}=\dot{n} c_{p} \ln \frac{T_{H} T_{L}}{T_{R}^{2}}
$$


e:

$$
\left\{\begin{array}{l}
\dot{n}_{H_{2}} \Delta h_{R}^{0}+\dot{n} c_{p}\left(T_{H}+T_{L}-2 T_{R}\right)=0 \\
T_{i g n}=\sqrt{T_{H} T_{L}} e^{\frac{\Delta s_{R}^{0}}{2 c_{p}}}
\end{array}\right.
$$

As temperaturas de ignição, abaixo usadas como comparativo foram retiradas da referência ASSOCIATION (2014).

As colunas $\overline{\dot{n} \times c_{p}}$ foram calculadas utilizando os polinômios de 7 coeficientes da NASA BRIDE; BURCAT (1994). A média foi calculada considerando temperaturas de $T_{L}=298 \mathrm{~K}$ até $T_{R}$ para os reagentes (combustível mais oxigênio estequiométrico) e de $T_{R}$ até $T_{H}$ (limitado a 6000K, que é o limite de validade dos polinômios) para os produtos de combustão completa. $\Delta h_{\text {comb }}^{0}$ e $\Delta s_{\text {comb }}^{0}$ foram calculados à temperatura de referência (temperatura de ignição).

Tabela 5.1: Comparativo das temperaturas de ignição da chama de máxima irreversibilidade com a temperatura de autoignição

\begin{tabular}{||cccccccc||}
\hline Comb. & $T_{\text {autoig }}$ & $T_{\text {ign }}$ irrevestac & $T_{H}$ & $\dot{n}_{\text {react }} \times c_{p_{\text {react }}}$ & $\dot{n}_{\text {prod }} \times c_{p_{\text {prod }}}$ & $\Delta h_{\text {comb }}^{0}$ & $\Delta s_{\text {comb }}^{0}$ \\
\hline \hline & $K$ & $K$ & $K$ & $J / K$ & $J / K$ & $k J / m o l$ & $J / m o l / K$ \\
\hline$H_{2}$ & 833 & 342 & 4971 & 43 & 52,7 & -242 & $-45,8$ \\
$C O$ & 878 & 248 & 4756 & 49,8 & 60,9 & -277 & $-83,8$ \\
$C H_{4}$ & 868 & 759 & 5705 & 110 & 172 & -800 & 0,464 \\
$C_{3} O H$ & 728 & 868 & 5175 & 113 & 171 & -672 & 52 \\
$C_{2} H_{6}$ & 745 & 859 & 6137 & 196 & 291 & -1426 & 54,3 \\
$C_{3} H_{8}$ & 723 & 888 & 6306 & 284 & 408 & -2044 & 105 \\
\hline
\end{tabular}


Tabela 5.2: Comparativo das temperaturas de ignição da chama de máxima irreversibilidade com a temperatura de ignição da chama reversível

\begin{tabular}{||cccccccc||}
\hline Comb. & $T_{\text {ign }}$ irrevestac & $T_{\text {ignrev }}$ & $T_{\text {Hrev }}$ & $\overline{\dot{n}_{\text {react }} c_{p_{\text {react }}}}$ & $\overline{\dot{n}_{\text {prod }} c_{p_{\text {prod }}}}$ & $\Delta h_{\text {comb }}^{0}$ & $\Delta s_{\text {comb }}^{0}$ \\
\hline & $K$ & $K$ & $K$ & $J / K$ & $J / K$ & $k J / m o l$ & $J / m o l / K$ \\
\hline$H_{2}$ & 342 & 1068 & 7405 & 46 & 60 & -248 & -55 \\
$C O$ & 248 & 663 & 5956 & 45,5 & 55,8 & -283 & -88 \\
$C_{4} H_{4}$ & 759 & 1814 & 7496 & 137 & 179 & -809 & $-6,3$ \\
$C_{3} O H$ & 868 & 2028 & 7311 & 141 & 177 & -680 & 46 \\
$C_{2} H_{6}$ & 859 & 1954 & 8336 & 242 & 297 & -1443 & 42 \\
$C_{3} H_{8}$ & 888 & 2003 & 8530 & 358 & 415 & -2066 & 88 \\
\hline
\end{tabular}

\subsection{Chama adiabática de duas fatias de má- xima irreversibilidade}

A chama adiabática de irreversibilidade (interna) estacionária é de fato uma chama adiabática de máxima irreversibilidade. Pode-se intuir, sem prova nesse momento, que ela é aquela em que os reagentes se transformam em produto com a velocidade ótima de transformação, confundida com a velocidade de chama ou de conversão.

O Lagrangeano (obtido com a função objetivo como sendo o trabalho perdido internamente e a restrição, obedecendo a primeira lei para uma chama adiabática) de nossa função é (estamos supondo $n_{\text {reag }} \bar{c}_{p_{\text {reag }}}=n_{\text {prod }} \bar{c}_{p_{\text {prod }}}=\bar{c}_{p}$ ):

$$
L=\dot{W}_{\text {perdido }}-\lambda\left(\dot{n}_{\text {reag }} c_{p_{\text {reag }}}\left(T_{L}-T_{R}\right)+\dot{n}_{\text {prod }} c_{p_{\text {prod }}}\left(T_{H}-T_{R}\right)+\dot{n}_{H_{2}} \Delta h_{R}^{0}\right)
$$


onde:

$$
\dot{W}_{\text {perdido }}=T_{R} \dot{S}_{\text {ger }}
$$

e:

$$
\dot{S}_{g e r}=\dot{n}_{H_{2}} \Delta s_{R}^{0}+\dot{n}_{\text {reag }} \bar{c}_{p_{\text {reag }}} \ln \frac{T_{L}}{T_{R}}+\dot{n}_{\text {prod }} \bar{c}_{p_{\text {prod }}} \ln \frac{T_{H}}{T_{R}}
$$


O ponto estacionário é obtido em se diferenciando o Lagrangeano da chama irreversível em relação às variáveis $\left(\lambda, T_{R}\right.$ e $\left.T_{H}\right)$ e igualando-se essas equações a zero. Obtém-se o extremo em se resolvendo as três equações simultaneamente:

$$
\frac{\partial L}{\partial T_{R}}=\Delta \dot{S}_{R}^{0}+\dot{n}_{\text {reag }} \bar{c}_{p_{\text {reag }}} \ln \frac{T_{L}}{T_{R}}+\dot{n}_{\text {prod }} \bar{c}_{p_{\text {prod }}} \ln \frac{T_{H}}{T_{R}}-\left(\dot{n}_{\text {reag }} \bar{c}_{p}+\dot{n}_{\text {prod }} \bar{c}_{p}\right) \lambda=0
$$

$$
\frac{\partial L}{\partial T_{H}}=\dot{n}_{\text {prod }} \frac{\bar{c}_{p_{\text {prod }}} T_{R}}{T_{H}}-\lambda \dot{n}_{\text {prod }} \bar{c}_{p_{\text {prod }}}=0
$$

$$
\frac{\partial L}{\partial \lambda}=\dot{n}_{\text {reag }} \bar{c}_{p_{\text {reag }}}\left(T_{L}-T_{R}\right)+\dot{n}_{\text {prod }} \bar{c}_{p_{\text {prod }}}\left(T_{H}-T_{R}\right)+\dot{n}_{H_{2}} \Delta h_{R}^{0}=0
$$

Resolvendo-se as equações 5.14, 5.15, e 5.16 obtém-se:

$$
\lambda=\frac{T_{R}}{T_{H}}
$$

Com:

$\Delta h^{0}{ }_{R}=-241,8 \frac{\mathrm{kJ}}{\mathrm{mol}}$

$\Delta s^{0}{ }_{R}=-44,4 \frac{\mathrm{J}}{\operatorname{mol} \times K}$

$\bar{c}_{p}=53,5 \frac{\mathrm{J}}{\mathrm{mol} \times K}$

A matriz Bordered Hessian, dada por:

$$
\left[\begin{array}{ccc}
0 & g_{1} & g_{2} \\
g_{1} & L_{11} & L_{12} \\
g_{2} & L_{21} & L_{22}
\end{array}\right]
$$


onde:

$\mathrm{f}=\dot{W}_{\text {perdido }}$

$\mathrm{g}={\overline{\dot{n}_{\text {reag }}}}_{c_{p_{\text {reag }}}}\left(T_{L}-T_{R}\right)+{\overline{\dot{n}_{\text {prod }}}}_{p_{\text {prod }}}\left(T_{H}-T_{R}\right)+\dot{n}_{H_{2}} \Delta h_{R}^{0}$;

$\mathbf{a}=\left(T_{R}, T_{H}\right)$;

e os índices representam em relação a que variável é aplicada a derivada parcial.

É negativo definida, pois a condição suficiente para tal é:

$$
\left|H_{1}^{B}\right|<0 \text { e }\left|H_{2}^{B}\right|>0
$$

onde:

$$
\left|H_{1}^{B}\right|=\left|\begin{array}{cc}
0 & g_{1} \\
g_{1} & L_{11}
\end{array}\right| \text { e }\left|H_{2}^{B}\right|=\left|\begin{array}{ccc}
0 & g_{1} & g_{2} \\
g_{1} & L_{11} & L_{12} \\
g_{2} & L_{21} & L_{22}
\end{array}\right|
$$

Onde:

$$
\left|H_{1}^{B}\right|=\left|\begin{array}{cc}
0 & -\left(c_{p_{\text {reag }}}+c_{p_{\text {prod }}}\right) \\
-\left(c_{p_{\text {reag }}}+c_{p_{\text {prod }}}\right) & L_{11}
\end{array}\right|=-\left(c_{p_{\text {reag }}}+c_{p_{\text {prod }}}\right)^{2}<0
$$

e 


$$
\begin{aligned}
& \left|H_{2}^{B}\right|=\left|\begin{array}{ccc}
0 & -\left(c_{p_{\text {reag }}}+c_{p_{\text {prod }}}\right) & c_{p_{\text {prod }}} \\
--\left(c_{p_{\text {reag }}}+c_{p_{\text {prod }}}\right) & -\frac{c_{p_{\text {reag }}+c_{p_{\text {prod }}}}}{T_{R}} & \frac{c_{p_{\text {prod }}}}{T_{H}} \\
c_{p_{\text {prod }}} & \frac{c_{\text {prod }}}{T_{H}} & -\frac{T_{R} c_{\text {prod }}}{T_{H}^{2}}
\end{array}\right|= \\
& \frac{c_{p_{\text {prod }}}\left(c_{p_{\text {prod }}}+c_{p_{\text {reag }}}\right)}{T_{H}^{2} T_{R}}\left(-2 c_{p_{\text {prod }}} T_{R} T_{H}+c_{p_{\text {prod }}} T_{H}^{2}+\left(c_{p_{\text {prod }}}+c_{p_{\text {react }}}\right) T_{R}^{2}\right)> \\
& >\frac{c_{p_{\text {prod }}}\left(c_{p_{\text {prod }}}+c_{p_{\text {reag }}}\right)}{T_{H}^{2} T_{R}}\left(\sqrt{\left.c_{p_{\text {prod }}}+c_{p_{\text {reag }}} T_{R}-\sqrt{c_{p_{\text {prod }}}} T_{H}\right)^{2}>0}\right.
\end{aligned}
$$

A taxa de trabalho perdido encontrado é portanto, máxima. Percebe-se que a temperatura de ignição da chama adiabática de máxima irreversibilidade interna é menor que a temperatura de ignição da chama reversível.

Caso a otimização acima reproduza uma chama real, isso indicaria a viabilidade da hipótese inicial e sugeriria ser o ponto de ignição a melhor escolha de referência exergética. Propõe-se, ainda, um princípio: o de que o trabalho perdido internamente é máximo. A adequação ou não de tal princípio para chamas de múltiplas fatias será objeto de estudos posteriores.

\subsubsection{Um pouco mais de Chamas contínuas}

Poder-se-ia imaginar que no limite de infinitas fatias ter-se-ia uma chama contínua, no entanto, os saltos, por menores que sejam, são parte integrante das chamas aqui propostas e a essência do "hot brick problem". A chama contínua tem sua promoção de variação de temperatura através de um processo de taxa de troca de calor, ao contrário das chamas descontínuas que têm a promoção de variação de temperatura por conta da taxa de trabalho recebido.

Conclui-se que o modelo de chama contínua não é o limite da chama de infinitas 
fatias. Elas incorporam paradigmas distintos de modelagem. 


\section{Capítulo 6}

\section{Conclusões}

Tiraram-se algumas conclusões:

Retirou-se a condição de caixa preta da chama de duas fatias no quesito temperatura e se determinou a temperatura de referência, interna ao volume de controle. Embora se tenha considerado a pressão de referência como constante, para se abrir a caixa preta e se possibilitar a otimização de uma chama de " $\mathrm{n}$ " fatias, falta-se determinar o potencial químico das espécies na interface da chama maximamente irreversível.

Formulou-se um princípio de otimização termodinâmico válido para um chama adiabática descontínua de 2 fatias e aplicável a uma chama de " $n$ " fatias.

Formulou-se um modelo termodinâmico de duas fatias de uma chama adiabática reversível.

A condição de referência adotada está em equilíbrio termodinâmico, obedecendo portanto à exigência da análise exergética. 
A chama contínua de temperatura variável, segundo o modelo formulado, não é um limite da chama reversível de infinitas fatias. Verificou-se que a mecânica de uma chama adiabática contínua é diferente da mecânica de uma chama adiabática descontínua e que portanto o paradigma de modelagem é distinto. Ficou demonstrado que a chama contínua seria uma chama com irreversibilidade interna sendo um máximo absoluto enquanto que a chama descontínua seria uma chama de irreversibilidade interna sendo um máximo relativo. O modelo descontínuo é uma outra possibilidade de se modelar uma chama termodinamicamente do que aquele que se conhece, e que não funciona.

Formulou-se um modelo termodinâmico para uma chama adiabática de irreversibilidade interna máxima. As temperaturas de auto-ignição são quantitativamente validadas pelas temperaturas de ignição das chamas maximamente irreversíveis, para todos os combustíveis analisados, exceto para o $\mathrm{H}_{2}$ e o $\mathrm{CO}$, cujas temperaturas calculadas resultaram em valores significativamente inferiores às temperaturas de auto-ignição. É possível que seja necessário um modelo com maior número de fatias para esses combustíveis. Deve-se ressaltar que a temperatura de ignição é um fenômeno cinético e que são normalmente estimadas analiticamente com técnicas que envolvem o conhecimento da estrutura molecular dos componentes.

Segundo o modelo adotado, para este tipo de sistema o trabalho perdido tem uma condição distinta do da entropia gerada. A temperatura de referência é calculada para a condição de trabalho perdido ser um máximo relativo. Não se determina a condição de referência ab initio.

Este estudo sugere que é possível que a criticalidade auto-organizada venha a ter uma conexão com a termodinâmica clássica. Caso o princípio aqui proposto de maximização do trabalho perdido internamente seja de fato verificado para 
uma chama de mútliplas fatias, ter-se-á, caso se encontre essa conexão, formulado um princípio que permita que se determine o estado estacionário de um sistema complexo (sistemas por definição abertos) que tenha variáveis termodinâmicas identificáveis. Posteriormente, em se introduzindo a variável tempo, determinar-se a dinâmica desses sistemas. A conexão temporal parece, dar-se-á através da determinação, por via experimental, da velocidade de transformação ou velocidade de chama. Isso determinaria as diferenças que seriam esperadas entre sistemas de combustíveis distintos. 


\section{Capítulo 7}

\section{Sugestão de trabalhos futuros}

Conhece-se a temperatura da interface de uma chama adiabática maximamente irreversível. O passo seguinte é o de se tentar modelar a composição química da interface dessa chama.

Conhecendo-se então a referência por completo, retira-se o sistema termodinâmico de duas fatias da condição de caixa preta e se define o perfil da chama de duas fatias.

Este será o objeto da próxima etapa desta pesquisa.

Como extensão, ainda, recomenda-se o encaminhamento do modelo multifatias de chama irreversível, o que chamamos de chamas termodinâmicas, conforme a figura 7.1 .

Tendo-se um princípio de otimização, parte-se então para abrir a caixa preta da chama de " $n$ " fatias com as espécies da chama de combustão em um passo.

Tendo-se a chama de incrementos de reação de um passo, dever-se-á então 


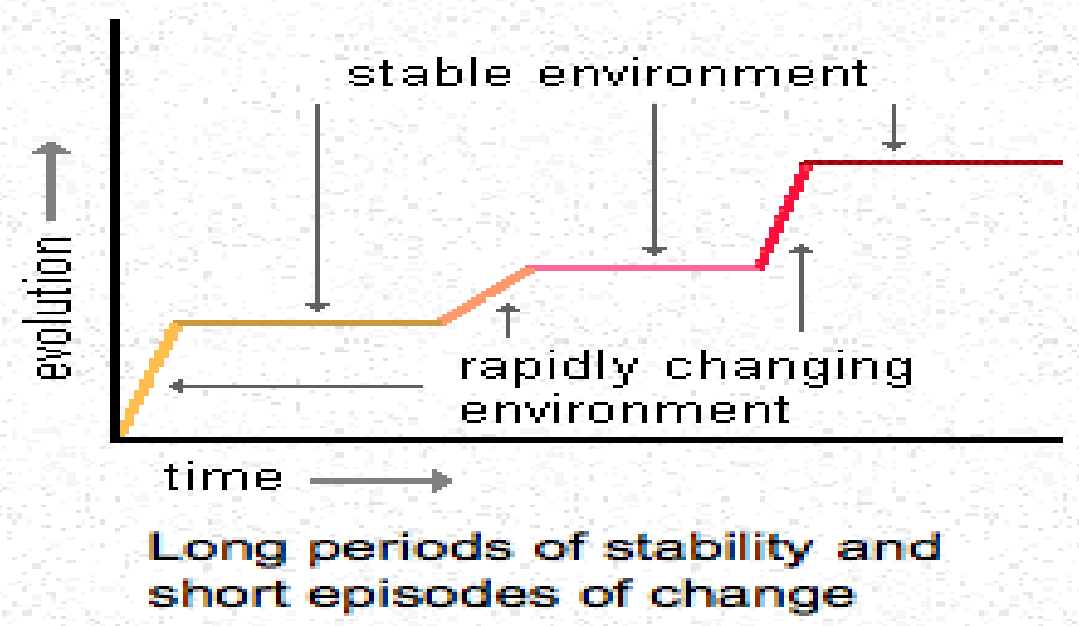

Figura 7.1: Gráfico esquemático de um sistema em evolução por equilíbrio pontuado (O'NEIL, 2017)

verificar o procedimento para se introduzir mais espécies químicas na simulação. A cada espécie nova que se introduz, o perfil vai se ajustando. 


\section{Referências Bibliográficas}

AHRENDTS, J. Reference states. Energy, Washington, DC, v. 5, n. 8-9, p. 667-677, 1979.

ARPACI, V.; SELAMET, A. Entropy production in flames. Combustion and Flame, v. 73, n. 3, p. 251-259, 1988.

ASSOCIATION, F. Fire Safety and Risk Management: for the NEBOSH National Certificate in Fire Safety and Risk Management. [S.I.]: Taylor \& Francis, 2014.

BAEHR, H. D. Die exergie der brennstoffe. B.W.K., v. 31, n. 7, p. 292-297, 1979.

BAK, P. How nature works : the science of self-organized criticality. [S.I.]: Copernicus, New York, NY, USA, 1996. 212 p.

BEJAN, A. Entropy generation minimization: The new thermodynamics of finitesize devices and finite-time processes. Journal of Applied Physics, AIP, v. 79 , n. 3, p. 1191-1218, 1996.

BERETTA, G. et al. On the concept of a reversible flame. Energy for the Transition Age, Flowers '92. 1992. 
BISIO, G.; RUBATTO, G. Thermodynamic analysis of chemically reacting systems; choice of a reference state for energy. Proceedings of the Intersociety Energy Conversion Engineering Conference, Las Vegas, NA, USA, v. 2, p. 890-899, 2000.

BOSNJAKOVIC, F. Bezugszustand der exergie eines reagiernden systems (reference states of the exergy in a reacting system). Forschung Im Ingenieurwesen Engineering Research, v. 20, p. 151-152, 1963.

BRIDE, B.; BURCAT, A. 1994 Ideal Gas Thermodynamic Data for Combustion and Air-Pollution Use. [S.I.: s.n.], December 1994.

BUCKMASTER, J. et al. Combustion theory and modeling. Proceedings of the Combustion Institute, Amsterdam, Netherlands, Elsevier, v. 30, n. 1, p. 1-19, 2005.

CHESKIS, S. Quantitative measurements of absolute concentrations of intermediate species in flames. Progress in Energy and Combustion Science, v. 25, n. 3, p. 233-252, 1999.

CLAVIN, P. Dynamic behavior of premixed flame fronts in laminar and turbulent flows. Progress in Energy and Combustion Science, v. 11, n. 1, p. 1-59, 1985.

CONAIRE, M. et al. A comprehensive modeling study of hydrogen oxidation. International Journal of Chemical Kinetics, John Wiley \& Sons, v. 36, n. 11, p. $603-622,2004$.

CURRAN, $H$. et al. A comprehensive modeling study of $n$-heptane oxidation. Combustion and Flame, v. 114, n. 1-2, p. 149-177, 1998. 
DENBIGH, K. The second-law efficiency of chemical processes. Chemical Engineering Science, v. 6, n. 1, p. 1-9, 1956.

DUHEM, P.; NEEDHAM, P. Commentary on the Principles of Thermodynamics by Pierre Duhem. Netherlands: Springer, 2011. 209 p. (Boston Studies in the Philosophy of Science, v. 277).

DUNBAR, W.; LIOR, N. Understanding combustion irreversibility. Second Law Analysis - Industrial and Environmental Applications. v. 25, p. 81-90, 1991.

ELDREDGE, N.; GOULD, S. J. Punctuated equilibria: an alternative to phyletic gradualism. In: Models in Paleobiology. San Francisco: Freeman Cooper, 1972. p. 82-115.

EVANS, D.; ANDRÁS, B. Possible variational principle for steady states far from equilibrium. Phys. Rev. Lett., American Physical Society, v. 67, p. 25972600, Nov 1991.

GAGGIOLI, R. The concept of available energy. Chemical Engineering Science, v. 16, n. 12, p. 87-96, 1961.

GALLO, W.; MILANEZ, L. Choice of a reference state for exergetic analysis. Energy, v. 15, n. 2, p. 113-121, 1990.

GARDINER, W. C. Gas-Phase Combustion Chemistry. [S.I.]: SpringerVerlag New York, 2000. 543 p.

GAYDON, A. G.; WOLFHARD, H. G. Flames; their structure, radiation and temperature. [S.I.]: Chapman and Hall, 1970. 401 p. 
GIBBS, J. W. The Collected Works of J. Willard Gibbs: Thermodynamics. [S.I.]: Yale University Press, 1948. 491 p. (The Collected Works of J. Willard Gibbs).

GLANSDORFF, P.; PRIGOGINE, I. Thermodynamics Theory of Structure, Stability and Fluctuations. [S.I.]: Wiley Interscience, 1971. 305 p.

GOUY, G. Sur l'énergie utilisable. J. Phys. Theor. Appl., v. 8, n. 1, p. 501$518,1889$.

HELD, T. J.; MARCHESE, A. J.; DRYER, F. L. A semi-empirical reaction mechanism for $n$-heptane oxidation and pyrolysis. Combustion Science and Technology, v. 123, n. 1-6, p. 107-146, 1997.

HILLERT, M.; ÅGREN, J. Extremum principles for irreversible processes. Acta Materialia, v. 54, n. 8, p. 2063-2066, May 2006.

HIRSCHFELDER, J.; CURTISS, C.; BIRD, R. Molecular theory of gases and liquids. New York: Wiley, 1955. 1219 p. (Structure of Matter Series).

HOFF, J. Die rolle des osmotischen drucks in der analogie zwischen losungen und gasen. Zeitschrift fur physikalische Chemie, v. 1, p. 481-508, 1887.

JONES, W.; LINDSTEDT, R. Global reaction schemes for hydrocarbon combustion. Combustion and Flame, v. 73, p. 233-249, 1988.

KEE, R. et al. A Fortran Computer Code Package For The Evaluation Of Gas-Phase, Multicomponent Transport Properties. [S.I.: s.n.], 1986.

KEE, R.; RUPLEY, F.; MILLER, J. The Chemkin Thermodynamic Data Base. [S.I.]: Sandia National Laboratories, 1987. 
KEE, R. J. A FORTRAN Program for Modeling Steady Laminar Onedimensional Premixed Flames. [S.I.]: Sandia National Laboratories, 1985. $116 \mathrm{p}$.

KEENAN, J. Thermodynamics. [S.I.]: John Wiley, 1941. 499 p.

KLEIN, M.; MEIJER, P. Principle of minimum entropy production. Phys. Rev., American Physical Society, v. 96, p. 250-255, Oct 1954.

KONNOV, A. Remaining uncertainties in the kinetic mechanism of hydrogen combustion. Combustion and Flame, v. 152, n. 4, p. 507-528, 2008.

KOTAS, T. The exergy method of thermal plant analysis. Butterworths: London, 1985. 328 p.

LAW, C. Combustion at a crossroads: status and prospects. Proceedings of the Combustion Institute, v. 31, n. 1, p. 1-29, 2007.

LIOR, N.; SARMIENTO-DARKIN, W.; AL-SHARQAWI, H. The exergy fields in transport processes: their calculation and use. Energy, v. 31, n. 5, p. 553-578, 2006.

LOZANO, M.; VALERO, A. Theory of exergetic cost. Energy, v. 18, n. 9, p. 939-960, 1993.

MARTYUSHEV, L.; SELEZNEV, V. Maximum entropy production principle in physics, chemistry and biology. Physics Reports, v. 426, n. 1, p. 1-45, 2006.

NISHIDA, K.; TAKAGI, T.; KINOSHITA, S. Analysis of entropy generation and exergy loss during combustion. Proceedings of the Combustion Institute, v. 29, n. 1, p. $869-874,2002$. 
OBERT, E. Thermodynamics. [S.I.]: McGraw-Hill Book Company, 1948. $571 \mathrm{p}$.

O'NEIL, D. Punctuated equilibria: an alternative to phyletic gradualism. 2017.

ONSAGER, L. Reciprocal relations in irreversible processes. Phys. Rev., American Physical Society, v. 37, p. 405-426, Feb 1931.

PALTRIDGE, G. The steady-state format of global climate. Quarterly Journal of the Royal Meteorological Society, John Wiley \& Sons, v. 104, n. 442, p. 927-945, 1978.

PALTRIDGE, G. Climate and thermodynamic systems of maximum dissipation. Nature, v. 279, p. 630-631, 1979.

POPE, S. Turbulent premixed flames. Annual Review of Fluid Mechanics, Palo Alto, CA, USA, v. 19, p. 237-270, 1987.

PRIGOGINE, I. Étude thermodynamique des phenomènes irréversibles. 1947. Tese (Doutorado) — Université libre de Bruxelles, Liège.

RATHAKRISHNAN, E. Fundamentals of Engineering Thermodynamics. [S.I.]: PHI Learning Pvt. Ltd., 2005. 716 p.

RATKJE, S.; ARONS, J. Denbigh revisited: reducing lost work in chemical processes. Chemical Engineering Science, v. 50, n. 10, p. 1551-1560, 1995.

REIS, H. Use and validity of principles of extremum of entropy production in the study of complex systems. Annals of Physics, v. 346, p. 22-27, 2014.

ROTH, B. A Theoretical Treatment of Technical Risk in Modern Propulsion System Design. 2000. Tese (Doutorado) - Georgia Institute of Technology. 
SOM, S.; DATTA, A. Thermodynamic irreversibilities and exergy balance in combustion processes. Progress in Energy and Combustion Science, v. 34, n. 3, p. 351-376, 2008.

STODOLA, A. Die dampfturbinen und die aussichten der warmekraftmaschinen. [S.I.]: J. Springer, 1903. 248 p.

SZARGUT, J. Die exergiebilanz der warmeprozesse in der huttenindustrie. Freiberger Forschungshefte, B, n. 68, p. 81-103, 1962.

SZARGUT, J. International progress in second law analysis. Energy, v. 5, n. 8-9, p. $709-718,1980$.

TABRIZI, F.; SHARAK, A.; SHARAK, A. Thermodynamic analysis of combustion processes and pollutants emission using nonlinear optimization approach. Asia-Pacific Journal of Chemical Engineering, v. 7, n. 1, p. 80-85, 2012.

TENG, H.; KINOSHITA, C.; MASUTANI, S. Entropy generation in multicomponent reacting fluid flow with heat and mass transfer. American Society of Mechanical Engineers, Advanced Energy Systems Division (Publication) AES, Atlanta, GA, USA, v. 36, p. 191-198, 1996.

TORIO, H. Exergy analysis of renewable energy-based climatisation systems for buildings: a critical review. Energy and Buildings, v. 41, n. 3, p. 248-271, 2009

VERHELST, S.; SHEPPARD, C. Multi-zone thermodynamic modelling of spark ignition engine combustion - an overview. Ener. Convers. Manag., v. 50, n. 5, p. 1326-1335, 2009. 
WARNATZ, J.; MAAS, U.; DIBBLE, R. Combustion: Physical And Chemical Fundamentals, Modeling And Simulation, Experiments, Pollutant Formation. [S.I.]: Springer, 2006. 378 p.

WEINBERG, F. The first half-million years of combustion research and today's burning problems. Progress in Energy and Combustion Science, v. 1, n. 1, p. 17-31, 1975.

WESTBROOK, C.; DRYER, F. Chemical kinetic modeling of hydrocarbon combustion. Prog. Energy Combustion Sci, v. 10, p. 1-57, 1984.

WESTBROOK, C. et al. Computational combustion. Proceedings of the Combustion Institute, v. 30, n. 1, p. 125-157, 2005.

WINTERBOTTOM, J.; KING, M.(Ed.). Reactor Design for Chemical Engineers. [S.I.]: Stanley Thornes (Publishers) Ltd, 1999. 454 p.

ZIEGLER, $\mathrm{H}$. Chemical reactions and the principle of maximal rate of entropy production. ZAMP Zeitschrift für angewandte Mathematik und Physik, v. 34, n. 6, p. 832-844, 1983.

ZIMAN, J. The general variational principle of transport theory. Can. J. Phys., v. 34, p. 1256-1273, 1956. 